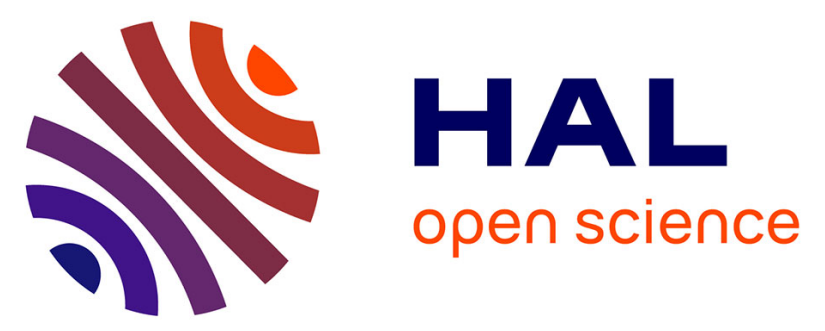

\title{
Artificial recharge of aquifers and pumping: transient analytical solutions for hydraulic head and impact on streamflow rate based on the spatial superposition method
}

\author{
Benoît Dewandel, Sandra Lanini, Vivien Hakoun, Yvan Caballero, \\ Jean-Christophe Maréchal
}

\section{To cite this version:}

Benoît Dewandel, Sandra Lanini, Vivien Hakoun, Yvan Caballero, Jean-Christophe Maréchal. Artificial recharge of aquifers and pumping: transient analytical solutions for hydraulic head and impact on streamflow rate based on the spatial superposition method. Hydrogeology Journal, 2021, 29 (3), pp.1009-1026. 10.1007/s10040-020-02294-9 . hal-03154763

\section{HAL Id: hal-03154763 https://hal-brgm.archives-ouvertes.fr/hal-03154763}

Submitted on 1 Mar 2021

HAL is a multi-disciplinary open access archive for the deposit and dissemination of scientific research documents, whether they are published or not. The documents may come from teaching and research institutions in France or abroad, or from public or private research centers.
L'archive ouverte pluridisciplinaire HAL, est destinée au dépôt et à la diffusion de documents scientifiques de niveau recherche, publiés ou non, émanant des établissements d'enseignement et de recherche français ou étrangers, des laboratoires publics ou privés. 
1 Artificial recharge of aquifers and pumping: transient analytical solutions for hydraulic head and impact on streamflow rate based on the spatial superposition method

3 Benoît Dewandel ${ }^{1,2}$ \& Sandra Lanini ${ }^{1,2}$ \& Vivien Hakoun ${ }^{1,2}$ \& Yvan Caballero ${ }^{1,2}$ \& Jean-

4 Christophe Maréchal ${ }^{1,2}$

51 BRGM, Univ Montpellier, Montpellier, France

2 G-eau, UMR 183, INRAE, CIRAD, IRD, AgroParisTech, Supagro, BRGM, Montpellier,

7 France

$8 *$ Corresponding author

\section{Abstract}

The behaviour of a transient groundwater mound in response to infiltration from surface basins has been studied for at least the past 80 years. Although analytical solutions are known for a large variety of situations, some common settings still lack a solution.

We remind and show that integrating the line-sink solution developed for pumping an unconfined aquifer by Hantush (1964a; 1965), considering the surface of the recharging area, is identical to his well-known solution for groundwater mounding below a rectangular basin (Hantush, 1967). This implies from a general standpoint that the principle of superposition can be used for directly implementing pumping wells, as well as aquifer boundaries, to a unique solution. Moreover, we show that other line-sink solutions, provided that partial differential equations behaviour is linear, can be used with a spatial superposition method for addressing a variety of hydrogeological settings.

Based on this trivial principle and on existing line-sink solutions, we propose several analytical solutions able to consider a rectangular recharging area and a pumping well in an unconfined aquifer: (i) near a stream, (ii) between a stream and a no-flow boundary, with and without the influence of natural recharge, (iii) near a stream that partially penetrates the aquifer and (iv) for a multi-layer aquifer. For cases including streams, transient solutions of the impact on streamflow rate are also established.

The proposed analytical solutions will be useful applications for Managed Aquifer Recharge, in particular the design of structures for artificially recharging an aquifer, possibly pumped by one or several wells. 
Hydrogeology Journal https://doi.org/10.1007/s10040-020-02294-9 - Feb.2021

30 Key words: groundwater mounding, pumping, stream, layered aquifer, analytical solutions, 31 Managed Aquifer Recharge. 


\section{Introduction}

Managed Aquifer Recharge (MAR) with surface water or treated wastewater, through trenches, basins, wells, dammed streams, canals, etc., is commonly used for limiting watertable decline, storing surface or storm water, controlling seawater intrusion, reducing land subsidence, or improving the quality of the injected water through geopurification (e.g., Bouwer, 2002; Aish, 2010; Ganot et al., 2017). MAR based on systems such as basins, dams, and specific irrigation practices (Yihdego, 2017), is used for enhancing groundwater resources in regions facing water scarcity because of limited precipitation and/or where aquifers are over-exploited (e.g., Dillon, 2005; Dillon et al., 2009; Bhuiyan, 2015; Massuel et al., 2014; Boisson et al., 2014, Lee et al., 2015; Stafford et al., 2015; Kacimov et al., 2016, Nicolas et al., 2019).

Before constructing MAR systems, their future efficiency must be evaluated, which requires fieldwork and drilling, monitoring of ground and surface water, and knowledge of aquifer properties (Dillon, 2005). Before starting detailed investigations and their subsequent modelling, analytical models can be used for a preliminary assessment of MAR opportunities. Such an assessment would be useful for different purposes, such as siting and pre-designing the recharging structures, assessing the groundwater mounding, evaluating the amount of water that can be stored and, finally, assess the impact of the MAR on nearby streams.

Since the early 1950s, several analytical solutions were developed for defining the growth and decay of groundwater mounds. These solutions consider infiltration from rectangular or circular basins with constant or transient recharging rates (Baumann, 1952; Glover, 1960; Hantush, 1967; Hunt, 1971; Marino, 1975; Latinopoulos, 1981; Warner et al., 1989; Rao and Sarma, 1981, Rai and Singh, 1996; Rai et al., 1998, 2001). For most of these solutions, flow from the recharge basin is assumed to be horizontal (Dupuit-Forchheimer assumption), occurring through an infinite, uniform and isotropic aquifer. Several authors evaluated these solutions against numerical modelling (e.g., Warner et al. 1989; Carleton, 2010) and showed that the seminal solution given by Hantush (1967) -one of the most widely used and cited (Finnemore, 1995; Zomorodi, 2005)- is very accurate. This solution assumes an infinite, unconfined, isotropic and horizontal aquifer (with Dupuit-Forchheimer assumption), and was obtained from an approximation of the Boussinesq partial differential equation (linearized form see Appendix A-1) by means of Laplace transform (Hantush, 1964a, b, 1967). Additional solutions were developed for considering other boundary conditions; these included a recharging area in aquifers with no-flow and constant-head boundaries (Marino, 
1974; Rao and Sarma, 1981, 1984; Latinopoulos, 1984; Molden et al., 1984; Manglik et al., 1997), or pumping wells near the MAR structure (Manglik et al., 2004). A recent solution also considered sloping aquifers (Zlotnik et al., 2017). Carleton (2010) conducted numerical experiments for evaluating the effect of vertical anisotropy in hydraulic conductivity on the shape of mounding; his results showed that the greater the horizontal hydraulic conductivity (i.e. $K_{h} / K_{v}>1$ ), the more the height of mounding by classical analytical solutions (e.g. Hantush, 1967) will be underestimated.

Existing works present analytical solutions for tackling complex hydrogeological settings, but some common settings still lack a solution. Such settings include, for example, assessment of the impact of MAR on a stream where an infiltration basin and pumping wells are located between the stream and a no-flow boundary, with or without natural recharge. Others are where infiltration basins and pumping wells are located close to a clogged stream, or the case of a multi-layer aquifer system.

We first remind and demonstrate that the Hantush (1967) solution can be found by integrating the line sink solution developed for pumping-test interpretation in an unconfined aquifer (Hantush, 1964a, 1965) over the surface of the recharging area. Then, based on existing line sink solutions and the application of the principle of superposition because of the linear property of partial differential equations, we present and discuss solutions where the aquifer is space-limited (Dirichlet's and/or no-flow boundary conditions), where a stream partially penetrates the aquifer, and for a multi-layer aquifer system. Theoretical cases (Fig. 1) are presented for a recharging area and a pumping well in four unconfined aquifer settings: i) an aquifer near a river (Fig. 1a); ii) an aquifer with a river and a no-flow boundary (strip aquifer), with and without the influence of natural recharge (Fig. 1b); iii) an aquifer near a stream with a clogged streambed that partially penetrates the aquifer (Fig. 1c); and iv) a recharging toplayer aquifer and pumping at the bottom of a semi-confined aquifer (Fig. 1d). In addition, we provide approximate but useful transient solutions for evaluating the impact of MAR (in terms of flow rate) on the stream, for the presented cases.

Our study seeks alternative transient analytical solutions based on the spatial superposition method for computing groundwater mounding (or depletion), or its impact on a stream while recharging and pumping unconfined aquifers. These solutions are useful and could be implemented in operational tools for engineers designing recharge structures, and/or 
improving the management of existing MAR structures. We do not suggest that the proposed solutions should replace existing analytical or numerical models used for modelling groundwater mounding. Rather, they are meant to supplement existing models for improving the design of such engineered systems.

\section{Mathematical statements}

Assuming an unconfined, infinite and horizontal aquifer, characterized by constant and uniform hydraulic conductivity and storativity (storage coefficient), and that groundwater flow is horizontal (Dupuit-Forchheimer assumption), Hantush (1964a, b, 1965) obtained an analytical solution of the hydraulic head for a well pumping in such an aquifer, from a linearized form of the Boussinesq equation (Appendix A-2) and by using Laplace transform. In this solution, the well is vertical, fully penetrates the aquifer and is pumped with a constant pumping rate $Q_{\text {Pump }}$ (here $Q_{\text {Pump }}<0$ ). Because of the Hantush's linearization (see Hantush, 1964a, b; 1965), the solution is applicable only when the declining levels with respect to the initial water-table depth do not exceed one-half of the initial aquifer thickness (ie: $h_{0^{-}}$ $h<0.5 h_{0}$ ). The transient evolution of hydraulic head at a location $x_{o b s}, y_{o b s}$ can be deduced from:

$$
Z_{\text {Pump }}\left(x_{o b s}, y_{o b s}, t\right)=h^{2}-h_{o}{ }^{2}=\frac{Q_{P u m p}}{2 \pi K} W\left(\frac{r^{2}}{4 v t}\right)
$$

with $h_{0}$ the initial hydraulic head, $h\left(\right.$ or $\left.h\left(x_{o b s}, y_{o b s}, t\right)\right)$ the hydraulic head at $t, v=\frac{K \bar{b}}{S}$, the diffusivity, $r=\sqrt{x_{o b s}^{2}+y_{o b s}^{2}}$, the distance to the pumping well, $K$ the hydraulic conductivity of the aquifer and $S$ the aquifer storativity. $W(u)$ is the well-function (or exponential integral, $\left.E_{l}(u)\right), \bar{b}$ is a constant of linearization that can be approximated by the average aquifer thickness at the point of interest $\left(\bar{b}=\frac{1}{2}\left(h_{0}+h_{t}\right)\right)$ and $t$ the period at the end of which $h$ is to be evaluated (Hantush, 1965; Warner et al.1989). Usually, $\bar{b}$ is estimated after several successive iterations (Hantush, 1967; Marino, 1967). Note that Eq. 1 is identical to the Theis solution (Theis, 1935) for a fully penetrating well in a confined isotropic aquifer, where drawdown is small in comparison to the aquifer thickness $\left(h_{0^{-}} h<<h_{0}\right)$, with $S$ here being the aquifer storage coefficient and $\bar{b}$ the aquifer thickness (in this case $\bar{b}=$ constant).

Because of the linear behaviour of the Hantush partial differential equation and assuming that the percolating water directly enters the aquifer (absence of vadose zone), Eq. 1 can be 
integrated into a rectangular surface to give a solution of groundwater mounding for a rectangular basin (Fig.2). Therefore, with a total recharging rate $Q_{\text {Rech }}\left(Q_{\text {Rech }}>0\right)$ the integration of Eq. 1 leads to the following expression:

$$
Z_{\text {Rech }}\left(x_{o b s}, y_{o b s}, t\right)=h^{2}-h_{o}{ }^{2}=\frac{1}{2 \pi K} \int_{-x_{L}}^{+x_{L}} \int_{-y_{L}}^{+y_{L}} \frac{Q_{R e c h}}{4 x_{L} y_{L}} W\left(\frac{\left(x-x_{o b s}\right)^{2}+\left(y-y_{o b s}\right)^{2}}{4 v t}\right) d x d y
$$

Where $2 x_{L}$ and $2 y_{L}$ characterize the rectangular recharging area lengths along the $x$-axis and the $y$-axis respectively. $x=y=0$ at the centre of the rectangle.

Assuming that the recharging rate, $R$, is uniformly distributed on the rectangular recharging area $\left(2 x_{L} \times 2 y_{L}\right), Q_{R e c h}$ can be expressed as a function of $R\left(R=\frac{Q_{R e c h}}{4 x_{L} y_{L}}\right)$, and it is shown that Eq. 2 is identical to the analytical solution of groundwater mounding for a rectangular basin with a uniform percolation rate (Fig.2), proposed by Hantush (1967); Eq. 3. Appendix B presents the demonstration. Note that the demonstration exposed in appendix presents similarities to that presented in Polubarinova-Kochina book (1977) and the one used for modelling drawdown of a pumping test in a well that intersects fractures (Dewandel et al., 2018).

$$
\begin{aligned}
Z_{\text {Rech }}\left(x_{o b s}, y_{o b s}, t\right) & =h^{2}-h_{o}{ }^{2} \\
= & \frac{R \bar{b}}{2 S} \int_{0}^{t}\left[\operatorname{Erf}\left(\frac{x_{L}+x_{o b s}}{2 \sqrt{v \tau}}\right)+\operatorname{Erf}\left(\frac{x_{L}-x_{o b s}}{2 \sqrt{v \tau}}\right)\right] \times\left[\operatorname{Erf}\left(\frac{y_{L}+y_{o b s}}{2 \sqrt{v \tau}}\right)+\operatorname{Erf}\left(\frac{y_{L}-y_{o b s}}{2 \sqrt{v \tau}}\right)\right] d \tau
\end{aligned}
$$

Assumptions and mathematical hypothesis of Eq. 3 are the same as the ones exposed before (see also Hantush 1967): unconfined, infinite and horizontal aquifer; Dupuit-Forchheimer assumption, the solution is a valid for $h-h_{0}<0.5 h_{0}$ and the infiltrating water directly enters the aquifer. Aquifer parameters are defined before.

Though 'mathematically trivial', these solutions can be easily used or combined for a large variety of hydrogeological settings based on mainly four interesting points. First, as already suggested by Hantush (1967), the principle of superposition (image-well theory) can be used with Eq. 3 for defining aquifer boundaries. For example, Molden et al. (1984) used this principle for modelling groundwater mounding from a rectangular basin near a stream, using Glover's (1960) analytical solution. However, their solution assumes that the mound's height 
152

153

154

155

156

157

158

159

160

161

162

163

164

165

166

167

168

169

170

171

172

173

174

175

176

177

178

179

180

181

is negligible compared to the initial saturated thickness (ie, $h-h_{0} \approx h_{0}$ ), which is not the case here. Second, it is possible to combine $Z$ pumping terms $\left(Z_{\text {Pump }}\right.$ in Eq. 1) and recharging areas ( $Z_{\text {Rech }}$ in Eq. 3) - and, by extension, aquifer boundaries - in a unique analytical solution for computing hydraulic head where recharging area and pumping wells are located in a spacelimited aquifer, such as between a river (using Dirichlet's condition) and a no-flow boundary. Third, Equation 1 can be integrated over any surface geometry (not necessarily a rectangle or a circle) and aquifer boundaries (if any) need not to be parallel or perpendicular to the basin geometry. Fourth and last, other line-sink solutions can be applied to consider other aquifer settings, provided that corresponding governing partial differential equation is linear and the use of the spatial superposition method. A similar theoretical approach was used by Zlotnik et al. (2017), who estimated the groundwater mounding of a rectangular basin in a sloping aquifer from the appropriate well solution (Hantush, 1964a, b). However, as Molden et al. (1984), their solution assumes that the mound's height is negligible compared to the initial saturated thickness and no solution including aquifer limits or stream was proposed.

Applying this principle of superposition, we propose alternative settings including a stream that partially penetrates the aquifer and a multi-layer aquifer system. In the following, $Z$ terms and other integrals were evaluated using the Gauss-Legendre quadrature.

\section{Theoretical examples with a stream fully penetrating the aquifer}

\subsection{Solutions for a rectangular recharging area and a pumping well near a stream}

\subsubsection{Hydraulic-head solution}

As noted above and because of the linear behaviour of the partial differential equation, an analytical solution can be obtained using the principle of superposition (image-well theory, Ferris et al., 1962; Kruseman and de Ridder, 1994; Dewandel et al., 2014) for a rectangular recharging area and a pumping well near a stream; Figs. 1a and 3a). The aquifer is unconfined and horizontal, and characterized by its hydraulic conductivity $(K)$ and its storativity $(S)$, and the stream fully penetrates the aquifer (constant-head boundary or Dirichlet's condition). For simplicity, the solution being provided in $Z$ terms, the hydraulic-head solution can be deduced from the following expression:

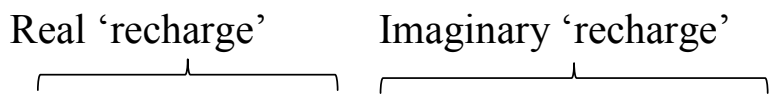




$$
\begin{aligned}
h^{2}-h_{o}{ }^{2}=\left[Z_{\text {Rech }}\left(x_{o b s}, y_{o b s}, t\right)-Z_{\text {Rech }}\left(2 d-x_{o b s}, y_{o b s}, t\right)\right] \\
\quad-\left[Z_{\text {Pump }}\left(x_{o b s}-x_{w}, y_{o b s}-y_{w}, t\right)-Z_{\text {Pump }}\left(2 d-\left(x_{o b s}+x_{w}\right), y_{o b s}-y_{w}, t\right)\right]
\end{aligned}
$$

182

$$
\text { Real 'well' }
$$

Imaginary 'well'

where $Z_{\text {Pump }}$ refers to Eq. 1 and $Z_{\text {Rech }}$ to Eq. 3. $x=y=0$ at the centre of the rectangular recharging area; $x_{w}$ and $y_{w}$ are the coordinates of the pumping well, and $d$ is the distance between the centre of the recharging area and the stream (Fig. 3a). Because of the linearization of partial differential equation, the solution is a valid for $\left|h-h_{0}\right|<0.5 h_{0}$.

Figure $4 \mathrm{a}$ gives an example of hydraulic head computations with Eq. 4 after 60 days of recharge, without and with a pumping well after 60 days of pumping. The recharging area is a square of $40 \mathrm{~m}$ sides, with a constant infiltration rate of $2.96 \times 10^{-6} \mathrm{~m} / \mathrm{s}$ (or a total infiltration rate of $17 \mathrm{~m}^{3} / \mathrm{h}$ ). The well is offset $140 \mathrm{~m}$ from the centre of the recharging area, between it and the stream. The pumping rate equals the infiltration rate (i.e. $17 \mathrm{~m}^{3} / \mathrm{h}$ ). The aquifer is characterized by $K=10^{-4} \mathrm{~m} / \mathrm{s}, S=0.05$. The stream is 200 metres from the centre of the recharging area.

\subsubsection{Impact of recharging area and pumping well on streamflow rate}

There are at least two ways to evaluate the impact in terms of streamflow rate $(\Delta q)$. First, it can be deduced from integration of the hydraulic-head gradient along the stream:

$\Delta q=K \bar{b} \int_{-\infty}^{+\infty} \frac{\partial h(d, y, t)}{\partial x} d y$

where $h(d, y, t)$ refers to Eq. 4 .

Second, and because of the linearity of partial differential equation, it can stem from two separate computations, one for the pumping well and another for the recharging area. For the pumping well (with coordinates $x_{w}$ and $y_{w}$ ), the impact on the stream is given by Glover and Balmer (1954):

$\Delta q_{\text {Pump }}=Q_{\text {Pump }} \operatorname{Erfc}\left(\sqrt{\frac{S\left(d-x_{w}\right)^{2}}{4 K h_{0} t}}\right)$

where $Q_{\text {Pump }}$ is the pumping rate $\left(Q_{\text {Pump }}<0\right)$ and $E r f c$ the complementary error function. Note that, at the edge of the stream, $\bar{b}$ is replaced by $h_{0}$, since drawdown is nil at $x=d$ $\left(h(d, \pm \infty, t)=h_{0}\right)$. 
For the recharge area, since the hydraulic-head solution for a rectangular recharging area is identical to the integration of the well solution for an unconfined aquifer over the same area, the superposition principle is still valid for evaluating the impact on the stream with Eq. $6 \mathrm{a}$. Therefore:

$$
\Delta q_{\text {Rech }}=\int_{-x_{L}}^{+x_{L}} \int_{-y_{L}}^{+y_{L}} \frac{Q_{r e c h}}{4 x_{L} y_{L}} \operatorname{Erfc}\left(\sqrt{\frac{S(d-x)^{2}}{4 K h_{0} t}}\right) d x d y=\int_{-x_{L}}^{+x_{L}} \frac{Q_{r e c h}}{2 x_{L}} \operatorname{Erfc}\left(\sqrt{\frac{S(d-x)^{2}}{4 K h_{0} t}}\right) d x
$$

An approximation of this solution can be obtained, if the $x$-length of the rectangular recharging area is small compared to the distance between recharging area and stream $(d$ $x_{L}>>2 x_{L}$, in practice a ratio of five is enough). Therefore, Eq. $6 \mathrm{~b}$ becomes the solution provided by Glover and Balmer (1954):

$$
\Delta q_{\text {Rech }}=Q_{\text {rech }} \operatorname{Erfc}\left(\sqrt{\frac{S d^{2}}{4 K h_{0} t}}\right)
$$

with $Q_{\text {Rech }}=4 x_{L} y_{L} R\left(Q_{R e c h}>0\right) ; R$ the uniform infiltration rate.

The approximate form of Eq. 5 can now be written as:

$\Delta q=\Delta q_{\text {Rech }}+\Delta q_{\text {Pump }}=Q_{\text {rech }} \operatorname{Erfc}\left(\sqrt{\frac{S d^{2}}{4 K h_{0} t}}\right)+Q_{\text {Pump }} \operatorname{Erfc}\left(\sqrt{\frac{S\left(d-x_{w}\right)^{2}}{4 K h_{0} t}}\right)$

which is easier to manipulate and of interesting practical use, as it allows adding as many terms as there are recharging areas and pumping wells.

Figure $4 \mathrm{~b}$ shows computations of the impact on the stream for the settings described on figures 1a and 3a. Aquifer parameters are the same as in Figure 4a. As expected, the integration of a hydraulic-head gradient along the stream (Eq. 5) and the approximate solution (Eq. 7) give similar results. These results show that over short times ( $<10$ days) the streamflow rate is reduced because of the short distance between well and stream. Over longer times (>20 days), the contribution of the recharging area becomes noticeable and the depletion flow-rate reduces, the impact on the stream reducing over time. By contrast, when 
the pumping well is located on the other side of the recharging area $\left(x_{w}=-140 \mathrm{~m}\right)$, the behaviour is reversed. After a short time, most water comes from the recharging area and streamflow increases. Then, the flow rate decreases because of the impact of the pumping well on the stream. However, in both cases, the equilibrium - nil influence on the stream as $Q_{\text {Pump }}=Q_{\text {rech }}$ (i.e. $\overline{Q_{\text {Rech }}}=-\overline{Q_{\text {Pump }}}$ ) - will be reached only after a very long time. When considering one recharging area and one pumping well, a nil impact right from the start of recharging and pumping occurs where these systems are equidistant from the stream (cf. Eq. 7).

3.2 Solutions for a rectangular recharging area and a pumping well between a stream and a no-flow boundary

\subsubsection{Hydraulic-head solution}

A solution for the hydraulic head for a rectangular recharging area and a pumping well between two parallel boundaries can also be found using the superposition principle, still because of the linearity of partial differential equation (e.g. Dewandel et al., 2014). Therefore, a generic solution for both terms (i.e. recharging area and pumping well) can be used for computing the hydraulic head in this setting:

$$
\begin{aligned}
Z_{2 \text { Limit }}=Z+ & \sum_{n=0,2,4 . .}^{\infty} b^{n / 2+1} c^{n / 2} Z\left(2 n L+2 d-x_{o b s}, y_{o b s}, t\right)+\sum_{n=2,4 . .}^{\infty}(b c)^{n / 2} Z\left(-2 n L-x_{o b s}, y_{o b s}, t\right) \\
& +\sum_{n=2,4 . .}^{\infty}(b c)^{n / 2} Z\left(2 n L-x_{o b s}, y_{o b s}, t\right)+\sum_{n=2,4 . .}^{\infty} b^{n / 2-1} c^{n / 2} Z\left(-(2 n L-2 d)-x_{o b s}, y_{o b s}, t\right)
\end{aligned}
$$

where $b$ and $c$ are coefficients associated with each boundary, $b$ or $c=1$ for a no-flow boundary, and $b$ or $c=-1$ for a constant-head boundary (stream, i.e Dirichlet's condition); $d$ is the distance between the centre of the recharging area and the stream, and $2 L$ is the distance between both limits (Fig. 3b), $x=y=0$ at the centre of the recharging area. For the pumping well, $x_{o b s}$ has to be replaced by $x_{o b s} x_{w}, y_{o b s}$ by $y_{o b s^{-}} y_{w}$, and $d$ by $d-x_{w} ; x_{w}$ and $y_{w}$ are coordinates of the pumping well. For the case of a rectangular recharging area, and a pumping well between a stream and a no-flow boundary, $b=-1$ and $c=1$. Note that this solution can be used for two parallel no-flow boundaries $(b=c=1)$ or two streams $(b=c=-1)$. To solve Eq.8a (but also the following Eqs.9), we used an algorithm based on an iterative process, where the number of images is defined when the absolute value given by the $\mathrm{n}^{\text {th }}$ computation becomes negligible. In the presented case (Fig.4c), computations were stopped when the value is lower 
259

260

261

262

263

264

265

266

267

268

269

270

271

272

273

274

275

276

277

than $4.10^{-7}$, which corresponds to 15 image wells. This criterion insures a high accuracy of computation.

As for the previous case, the aquifer is unconfined and horizontal, and characterized by its hydraulic conductivity $(K)$, its storativity $(S)$, and the solution is a valid for $\left|h-h_{0}\right|<0.5 h_{0}$.

The hydraulic-head solution can now be found from:

$h^{2}-h_{o}{ }^{2}=Z_{2 \text { Limit }_{\text {Rech }}}+Z_{2 \text { Limit_Pump }}$

where $Z_{2 \text { Limit_Rech }}$, refers to the component of the recharging rectangular area and $Z_{2 \text { Limit_Pump }}$ to the pumping well. Both expanded expressions are given in Appendix C.

Figure $4 c$ gives examples of hydraulic-head computations with Equation 8b. Aquifer parameters, distance to stream, infiltration rate, pumping location and flow rate are identical to the previous case (Fig. 4a). The no-flow boundary is located at $400 \mathrm{~m}$ from the centre of the recharging area, creating a $700 \mathrm{~m}$-wide strip aquifer. Hydraulic-head computations were done with and without pumping from the well after 60 days of recharging and pumping. Compared to the example without a no-flow boundary (Fig. 4a), the hydraulic head is slightly higher everywhere for the case without pumping. With an active pumping well, the head is slightly higher west of the recharging area, and slightly lower because of pumping to the east.

\subsubsection{Impact of recharging area and pumping well on streamflow rate}

As above, the impact on streamflow can be evaluated either from Eq. 5, or separately. For the pumping well, the impact on stream flow is given by Lelièvre (1969):

$$
\begin{aligned}
\Delta q_{\text {Pump }}=Q_{\text {Pump }} & {\left[\operatorname{Erfc}\left(\sqrt{\frac{S\left(d-x_{w}\right)^{2}}{4 K h_{0} t}}\right)\right.} \\
& \left.+\sum_{n=1,2,3 . .}^{\infty}(-1)^{n}\left(\operatorname{Erfc}\left(\frac{4 n L+\left(d-x_{w}\right)}{2 \sqrt{K h_{0} t / S}}\right)-\operatorname{Erfc}\left(\frac{4 n L-\left(d-x_{w}\right)}{2 \sqrt{K h_{0} t / S}}\right)\right)\right]
\end{aligned}
$$

For the recharging area and using the same development as in the previous case, an approximate solution can be found, if $\left(d-x_{L}\right)>>2 x_{L}$. It takes a similar form: 


$$
\Delta q_{\text {Rech }}=Q_{\text {Rech }}\left[\operatorname{Erfc}\left(\sqrt{\frac{S d^{2}}{4 K h_{0} t}}\right)+\sum_{n=1,2,3 . .}^{\infty}(-1)^{n}\left(\operatorname{Erfc}\left(\frac{4 n L+d}{2 \sqrt{K h_{0} t / S}}\right)-\operatorname{Erfc}\left(\frac{4 n L-d}{2 \sqrt{K h_{0} t / S}}\right)\right)\right]
$$

283

284

Under this condition, the impact on streamflow results from the sum of the two components in a form like Eq. $7\left(\Delta q=\Delta q_{\text {Rech }}+\Delta q_{\text {Pump }}\right)$. This form is also easier to manipulate and allows adding as many terms as there are recharging areas and pumping wells.

Figure $4 \mathrm{~d}$ shows computations of the impact on stream flow for the setting described on Figure 4c. The aquifer parameters are the same as in Figure $4 \mathrm{a}$. As before, the integration of a hydraulic-head gradient along the stream (Eq. 5) and the approximate solution (Eq. 9a+Eq. 9b) are in good agreement. The impact on streamflow, for a pumping well located east of the recharging area, or one to the west between the recharge area and the noflow boundary, is similar to that on Figure 4b: river depletion linked to the pumping well and flow towards the river linked to the recharging area, respectively. However, compared to the semi-finite aquifer, the relaxation time is shorter and a quasi-steady-state is reached earlier because of the limited extent of the aquifer.

\subsubsection{Steady-state solution of hydraulic head for an infinite strip aquifer along the y-axis,} limited by a river and a no-flow boundary: the case of natural recharging

In this case, $b=-1$ and $c=1,2 x_{L}=2 L, d=L, \mathrm{y}_{\mathrm{L}} \rightarrow \infty$ and $t \rightarrow \infty$ (steady-state) in the solution for the recharging area (Eq. C-2). Figure 5a shows the computation of hydraulic heads for natural recharge only. Aquifer parameters, distance to stream and distance to no-flow boundary are identical to those on Figure 4c. We consider a uniform distribution of natural recharge $(R)$ at a rate of $1.27 \times 10^{-8} \mathrm{~m} / \mathrm{s}$ (i.e. $400 \mathrm{~mm} /$ year). The solution is the same as that of Bruggeman (1999; sol. 21.11, p. 24; and Eq. 10, below), which corresponds to the hydraulic-head profile for a steady-state condition caused by recharge from precipitation $(R)$ through an infinite strip of width $2 L$, bounded on one side by a stream and on the other by a no-flow boundary. The error to Bruggeman's solution is very low (standardized root mean square error: $1.3 \times 10^{-5}$ ). Other tests are presented in Appendix C. Even for the extreme case of a very thin aquifer $\left(h_{0}=1.5 \mathrm{~m}\right.$; Appendix C), we found very consistent results, with little differences probably linked to numerical error (standardized Root Mean Square Error $<2 \times 10^{-5}$ ). Furthermore, the small errors prove that the numerical evaluation of the integrals is accurate.

Consequently, for a long time span (i.e. steady-state; $t \rightarrow \infty$ ), the solution tends to: 
$Z_{\text {NaturalRech }}=h^{2}-h_{o}{ }^{2}=\frac{R}{K}\left(4 L^{2}-(x+L)^{2}\right)$

312 with $x=0$ at the centre of the strip.

313 To include a mean annual aquifer recharge with artificial recharging areas and pumping wells, 314 Eq. 10 can be combined with Eq. 8b, providing an analytical solution for the hydraulic head in 315 the hydrogeological setting presented above $\left(h^{2}-h_{o}{ }^{2}=Z_{2 \text { Limit }_{\text {Rech }}}+Z_{2 \text { Limit }_{\text {Pump }}}+\right.$ $\left.Z_{\text {NaturalRech }}\right)$. The impact on the stream of the recharging structure and the pumping well, can also be evaluated from Eq. 5, but both are identical to the previous case (Eqs. 9a, b) because of the superposition theory. Figure $5 \mathrm{~b}$ shows an example with a recharging area and a pumping well at $140 \mathrm{~m}$ from the centre of the recharging area, after 1 day and 60 days of recharging and pumping. All other parameters are the same as above (Figure 4c).

\section{Theoretical examples for other aquifer settings}

Here we explore how other line-sink solutions can consider other aquifer settings, provided that governing partial differential equations are linear. For a pumping well, a generic solution of hydraulic head is given by:

$Z_{\text {Pump }}\left(x_{o b s}, y_{o b s}, t\right)=h^{2}-h_{o}{ }^{2}=\frac{Q_{P u m p}}{2 \pi K} f\left(x_{o b s}, y_{o b s}, t, \bar{b}, \alpha, \beta, \gamma \ldots\right)$

where $f\left(x_{o b s}, y_{o b s}, t, \bar{b}, \alpha, \beta, \gamma_{\ldots}\right)$ is a line-sink solution, for example an existing analytical solution for a well pumping a specific unconfined aquifer defined by parameters $\alpha, \beta, \gamma \ldots$, with $Q_{\text {Pump }}<0$.

For a rectangular recharging area-but this is applicable to all surface geometry-and assuming a uniform percolation rate, Eq. 2 can be generalized using spatial superposition method as follows:

$Z_{\text {Rech }}\left(x_{o b s}, y_{o b s}, t\right)=h^{2}-h_{o}{ }^{2}=\frac{R}{2 \pi K} \int_{-x_{L}}^{+x_{L}} \int_{-y_{L}}^{+y_{L}} f\left(x_{o b s}, y_{o b s}, t, \bar{b}, \alpha, \beta, \gamma \ldots\right) d x d y$ 
Eq. 11b may have an analytical form, or it can be evaluated numerically (e.g. by GaussLegendre quadrature). Combined with Eq. 11a, one obtains the solution for a setting where artificial recharge takes place through a rectangular area and pumping from a well. Because of the linearization of partial differential equations, the solution is a valid for $h-h_{0}<0.5 h_{0}$. In the following, no boundary condition were implemented, therefore $h( \pm \infty, y, t)=h(x, \pm \infty, t)=h_{0}$ (or $Z( \pm \infty, y, t)=Z(x, \pm \infty, t)=0)$.

\subsection{Solutions for partial stream penetration and a partially clogged streambed}

\subsubsection{Hydraulic-head solution}

The solutions are derived from Hunt's (1999) analytical solutions. In this conceptual model (Fig. 1c), the groundwater flux is assumed to be horizontal (Dupuit-Forchheimer assumption), the aquifer is unconfined, infinite and horizontal, and characterized by its hydraulic conductivity and storativity. This solution assumes that streambed penetration of the aquifer and dimensions of the streambed cross section are all relatively small compared to aquifer thickness, and that stream level is constant and maintained at the initial groundwater level (i.e., $h_{0}$ ). It also assumes that the streambed is partially clogged and that a linear relationship exists between the seepage rate through the streambed and the change in hydraulic head across the semi-pervious clogging layer.

\subsubsection{Hydraulic-head solution}

Assuming the linearized form of the Boussinesq equation as in Hantush (1967), for an unconfined aquifer, and after a change of variables (see Appendix D), Hunt's (1999) solution for hydraulic head and for a pumping well, expressed in term of $Z$, can be re-written as follows:

$$
\begin{aligned}
Z_{\text {HuntPump }}\left(x_{o b s}, y_{o b s}, t\right) & =h^{2}-{h_{o}}^{2} \\
= & \frac{Q_{\text {Pump }}}{2 \pi K}\left[W\left(\frac{x_{o b s}{ }^{2}+y_{o b s}{ }^{2}}{4 v t}\right)-\int_{0}^{1} W\left(\frac{\left(d+\left|d-x_{o b s}\right|-2 K \bar{b} L n(u) / \lambda\right)^{2}+y_{o b s}{ }^{2}}{4 v t}\right) d u\right]
\end{aligned}
$$

with $\lambda=\frac{b}{b^{\prime \prime}} k^{\prime \prime} ; b$ is the stream width, $b^{\prime \prime}$ the streambed thickness, $k$ ' the streambed hydraulic conductivity, and $Q_{\text {Pump }}(<0)$ the pumping flow-rate. Here, $x=y=0$ at the pumping well. Note that when $\lambda \rightarrow 0$ (i.e. impervious streambed), Eq. 12a gives Eq.1; and also when $\lambda \rightarrow \infty$ (stream 
fully penetrating the aquifer), Eq. 12a gives the hydraulic-head solution for a pumping well near a stream with zero drawdown (Theis, 1941; Glover and Balmer, 1954; see also § 3.1.1.).

According to the demonstration given in section 2, the hydraulic-head solution for a rectangular recharging area can be found by integrating Eq. 12a into the rectangular area $\left(2 x_{L} \times 2 y_{L}\right)$. Therefore, we obtain:

$$
\begin{aligned}
Z_{\text {HuntRect }}\left(x_{o b s}, y_{o b s}, t\right) & =h^{2}-h_{o}{ }^{2} \\
= & \frac{R \bar{b}}{2 S}\left\{\int_{0}^{t}\left[\operatorname{Erf}\left(\frac{x_{L}+x_{o b s}}{2 \sqrt{v \tau}}\right)+\operatorname{Erf}\left(\frac{x_{L}-x_{o b s}}{2 \sqrt{v \tau}}\right)\right] \times\left[\operatorname{Erf}\left(\frac{y_{L}+y_{o b s}}{2 \sqrt{v \tau}}\right)+\operatorname{Erf}\left(\frac{y_{L}-y_{o b s}}{2 \sqrt{v \tau}}\right)\right] d \tau\right. \\
& -\int_{0}^{t} \int_{0}^{1}\left[\operatorname{Erf}\left(\frac{x_{L}+\left(d+\left|d-x_{o b s}\right|+2 K \bar{b} L n(u) / \lambda\right)}{2 \sqrt{v \tau}}\right)\right. \\
+ & \left.\operatorname{Erf}\left(\frac{x_{L}-\left(d+\left|d-x_{o b s}\right|+2 K \bar{b} L n(u) / \lambda\right)}{2 \sqrt{v \tau}}\right)\right] \times\left[\operatorname{Erf}\left(\frac{y_{L}+y_{o b s}}{2 \sqrt{v \tau}}\right)\right. \\
& \left.\left.+\operatorname{Erf}\left(\frac{y_{L}-y_{o b s}}{2 \sqrt{v \tau}}\right)\right] d u d \tau\right\}
\end{aligned}
$$

with $x=y=0$ at the centre of the recharging area.

As mentioned before, this solution also assumes that the percolating water directly enters the aquifer (no vadose zone). Therefore, the sum of both $Z$ terms, similar to Eq. $8\left(h^{2}-h_{o}{ }^{2}=\right.$ $Z_{\text {HuntRect }}+Z_{\text {HuntPump }}$ ), gives the hydraulic-head solution for a rectangular recharging area and a pumping well located near a partially clogged stream. As before, the solution assumes that the decline, or rise, of the groundwater mound in case of recharging, should not exceed one-half of the initial saturated thickness $\left(\left|h-h_{0}\right|<0.5 h_{0}\right)$.

\subsubsection{Impact of recharging area and pumping well on stream flow rate}

According to Hunt (1999), the impact on a stream is given by:

$\Delta q=\lambda \int_{-\infty}^{+\infty} h(d, y, t) d y$

and can also be evaluated separately for the pumping well (Hunt, 1999) as: 


$$
\begin{aligned}
\Delta q_{\text {HuntPump }}= & Q_{\text {Pump }}\left[\operatorname{Erfc}\left(\sqrt{\frac{S\left(d-x_{w}\right)^{2}}{4 K \bar{b} t}}\right)\right. \\
& \left.-e^{\left(\frac{\lambda^{2} t}{4 S K \bar{b}}+\frac{\lambda\left(d-x_{w}\right)}{2 K \bar{b}}\right)} \operatorname{Erfc}\left(\sqrt{\frac{\lambda^{2} t}{4 S K \bar{b} t}}+\sqrt{\frac{S\left(d-x_{w}\right)^{2}}{4 K \bar{b} t}}\right)\right]
\end{aligned}
$$

379 For the rectangular recharging area, an approximate solution can also be given if $\left(d-x_{L}\right)>>2 x_{L}$ for the impact on the stream. It takes a similar form, while replacing $d-x_{w}$ by $d$ and $Q_{P \text { Pump }}$ by $Q_{\text {Rech }}\left(Q_{\text {Rech }}=4 x_{L} y_{L}\right)$ in Eq. 13b. Eq. 13a, with the appropriate solution for $h$, can also be used. Therefore, an approximate solution involving a recharging area and a pumping well is also found, taking a similar form as the previous cases (i.e., $\Delta q=\Delta q_{\text {RechHunt }}+$ $\left.\Delta q_{\text {PumpHunt }}\right)$.

Figures $6 \mathrm{a}$ and $\mathrm{b}$ give computation examples of hydraulic head and impact on streamflow rate for the aquifer setting described above, with various stream leakance values $\left(\lambda=\infty, 10^{-4}, 5.10^{-}\right.$ ${ }^{5}, 10^{-5}, 5.10^{-6}$ and $10^{-6} \mathrm{~m} / \mathrm{s}$ ), the stream being $10 \mathrm{~m}$ wide. Aquifer properties are identical to previous examples $\left(K=10^{-4} \mathrm{~m} / \mathrm{s}, S=0.05, h_{0}=12 \mathrm{~m}\right)$ and the stream is offset $300 \mathrm{~m}$ from the centre of the recharging area $\left(x_{L}=y_{L}=40 \mathrm{~m}, R=2.96 \times 10^{-6} \mathrm{~m} / \mathrm{s}\right)$. The pumping well is located between the stream and the recharging area, $140 \mathrm{~m}$ from the centre of the latter. The recharging area and pumping well have equal injection/pumping rate $\left(Q_{\text {Rech }}=Q_{\text {Pump }}=17 \mathrm{~m}^{3} / \mathrm{h}\right)$. For $\lambda=\infty$, the hydraulic head profile and its impact on the stream are, as expected, identical to Eq. 4 (stream fully penetrating the aquifer). For lower $\lambda$ values the clogging increases and stream-aquifer exchanges are reduced, the hydraulic head being lower near the stream. Consequently, the impact on streamflow rate is lowered and delayed as $\lambda$ decreases (Fig. 6b). This figure also shows that the approximate solution for evaluating the impact on the stream (Eq. 13b, with $\Delta q=\Delta q_{\text {RechHunt }}+\Delta q_{\text {PumpHunt }}$ ) is in good agreement with Eq. 13a.

\subsection{Solutions for a rectangular recharging area and a pumping well in a multi-aquifer system}

In this last case, we consider a recharging area on top of a multi-layer aquifer (Fig. 1d). The recharging area feeds an unconfined aquifer layer and pumping occurs in the deeper semiconfined layer. Recharging of the top layer induces a rise in hydraulic head in the deeper layer, but pumping there induces depletion in the upper layer. The system is characterized by 
an upper aquifer with hydraulic conductivity $K_{l}$ and storage coefficient (or storativity) $S_{l}$, and a deeper aquifer with transmissivity $T_{2}$ and storage coefficient $S_{2}$. The aquifers are separated by an aquitard of hydraulic conductivity $k^{\prime}$ and thickness $e^{\prime}$. Horizontal flow is assumed in both aquifers. The line-sink solutions for this conceptual model are extensions of the Hunt and Scott (2007) two-aquifer model.

For the given example (Figs. $7 \mathrm{a}, \mathrm{b}, \mathrm{c}$ ), $K_{l}=10^{-4} \mathrm{~m} / \mathrm{s}, S_{l}=0.05$ and $h_{0}=12 \mathrm{~m}$ are identical to previous cases, as are $T_{2}=10^{-4} \mathrm{~m}^{2} / \mathrm{s}, S_{2}=10^{-3}$ and ratio $k^{\prime} / e^{\prime}=5 \times 10^{-7} \mathrm{~s}^{-1}$. The recharging area and pumping distances are the same as before. Figures $7 \mathrm{a}$ and $\mathrm{b}$ are two examples of hydraulichead profiles at $\mathrm{t}=1$ day and $\mathrm{t}=60$ days in the top unconfined layer (Fig. 7a), and drawdown or rise in the deeper layer (Fig. 7b). A comparison between our solution and Hantush's one with a pumping well (Eq. 4 with $K=10^{-4} \mathrm{~m} / \mathrm{s}, h_{0}=12 \mathrm{~m}, S=0.05$ and $d \rightarrow \infty$ ) reveals that, near the recharging area, hydraulic heads from our solution are lower than Hantush's. This difference stems from the percolation of water towards the deeper aquifer layer (Fig. 7b). The recharging area induces a rise of water levels in the deep aquifer of up to $0.7 \mathrm{~m}$ at $\mathrm{t}=1$ day and up to $1.1 \mathrm{~m}$ at $\mathrm{t}=60$ days. Hydraulic heads in the top aquifer layer are impacted by the well pumping from the deeper layer; these heads are depleted by up to $0.6 \mathrm{~m}$ and $1.4 \mathrm{~m}$ after $\mathrm{t}=1$ day and 60 days, respectively.

To evaluate the flow rate entering the deeper aquifer layer, we computed the accumulated volume that was abstracted/recharged up to a given time from/into each aquifer. This computation was done by integrating the difference in hydraulic head in the $x-y$ plane of the top layer, multiplying this difference by the aquifer storativity, and subtracting the resulting volume from the volume of water added by recharging. Finally, a vertical drainage rate was computed for the entire system and compared to the rate stemming from the recharging area only (without pumping).

In the example shown on Fig. 7c, recharging and pumping rates are identical. Drainage results not only from the recharging area (top layer) to the deeper layer, but also from pumping the deep layer (percolation from the top layer). Over longer times, the computed drainage rate $\left(16.6 \mathrm{~m}^{3} / \mathrm{h}\right)$ almost counterbalances the pumping rate from the deeper aquifer layer $\left(17.0 \mathrm{~m}^{3} / \mathrm{h}\right)$. However, comparing this result to the situation where there is only a recharging area (without pumping well) shows that drainage rate from the recharging area to the deeper aquifer layer is minor $\left(0.4 \mathrm{~m}^{3} / \mathrm{h}\right)$. This shows that pumping in the deeper layer has a greater drainage effect on the top aquifer layer because of the large cone of depression induced by 
pumping, than the water infiltrating from the top layer and recharging the deep aquifer. In the latter case, only a small amount of water infiltrated by the recharging basin benefits the pumping well.

\section{Discussion and Conclusions}

The integration of the line-sink solution developed for unconfined aquifers (Hantush, 1964a, b, 1965) over the surface of a recharging area is mathematically identical to the well-known solution of Hantush (1967). The latter solution allows characterizing the rise and decline of a groundwater mound in response to uniform infiltration from a rectangular basin, obtained from a linearized form of the Boussinesq equation and Laplace transform (see the text for mathematical assumptions). This is a consequence of the linearity of the partial differential equation, and implies that the principle of superposition can be used to directly implement aquifer boundaries, as earlier suggested by Hantush (1967), as well as pumping wells.

Therefore, analytical solutions for hydraulic head are first proposed for two common hydrogeological settings: (i) a rectangular recharging area and a pumping well near a stream (Dirichlet's condition), and (ii) a rectangular recharging area and a pumping well between a stream and a no-flow boundary. We show that, under steady-state conditions, the analytical solution developed for the second setting is equivalent to Bruggeman's (1999) solution for a hydraulic-head profile resulting from recharge over an infinite strip bounded on one side by a stream and on the other side by a no-flow boundary. Therefore, a solution is proposed for the hydrogeological setting (ii) and the influence of natural recharge.

We also propose transient solutions for evaluating the impact on streamflow rate of a recharging area and a pumping well. Even though, rigorously, the impact must be computed by integrating the hydraulic gradient along the stream (Eq.5), we demonstrate that approximate solutions provide accurate results that can be used in most cases, as long as the distance from the side of the recharging area to the stream is small in comparison to the $x$ length of the recharging area. Such approximate solutions are identical to the existing analytical solution for evaluating the impact of a pumping well on a stream (e.g., Glover and Balmer, 1954; Lelièvre, 1969), and can be combined for separately evaluating the impacts from the recharging area and the pumping well. From a practical viewpoint, these solutions can be used with any number of recharging areas and pumping wells. In the given examples, where infiltration and pumping rates are equal, equilibrium, i.e. nil impact on streamflow rate, 
was not reached even after one year. This result shows that managed artificial recharge design must account for transient behaviour, and that the location of recharging areas and pumping wells must be carefully considered to avoid streamflow rate depletion, or contrarily that a significant part of the recharging water percolates straight into the stream.

We also propose a generic analytical solution for modelling transient hydraulic head in more complex aquifer settings with impact on streamflow rates, based on the integration of solutions over the recharging area. This provides the possibility of using other line-sink solutions for considering other aquifer settings, provided that governing partial differential equations are linear. We first derived from Hunt (1999) a solution involving a rectangular recharging area and a pumping well near a stream (with a clogged streambed) that partially penetrates the aquifer. Our results show that the solution proposed by Hunt (1999) for evaluating the impact of a pumping well on a stream, also appears to be a good approximation for evaluating the impact of a recharging area.

An example for a multi-layer aquifer, with and without a pumping well, is also given. . The solution computes hydraulic head in both layers, while recharging and pumping the upper and deeper layers, respectively. This solution allows evaluating the rise and/or decline of water levels in both layers, as well as evaluating the vertical drainage flow-rate between the upper and deeper layers. In the example shown, the impact on the deeper aquifer of the recharging area in terms of vertical drainage is lower than the impact of pumping the deeper aquifer on the near-surface layer, illustrating that only little water infiltrating from the basin really benefits the deeper aquifer.

Impacts on streamflow rate are given for the whole stream, but it may be of interest to evaluate it over a particular length. This can be achieved with Eq. 5 or Eq. 13a while integrating solutions for the appropriate interval. The total volume of stream depletion or rise over a certain time, can be evaluated by integrating the flow-rate solution over that period. Analytical solutions for the cases presented on Figures 2 and 3 can be found, e.g., in Hantush (1965) and Lelièvre (1969). We also consider that other existing analytical solutions, obtained for stream depletion created by a well on other aquifer settings (e.g. Hunt, 2014), may be valid approximate solutions for evaluating the impact of recharging areas.

Recharging or pumping-rate variations, not considered here, can also be incorporated using the principle of superposition on $Z$ terms (e.g. Hantush, 1967). The solutions developed here are applicable when the rise or decline in the unconfined aquifer is less than one-half of the 
500

501

502

503

504

505

506

507

508

509

510

511

512

513

514

515

516

517

518

519

520

521

522

523

524

525

526

initial saturated aquifer thickness $\left(\left|h-h_{0}\right|<0.5 h_{0}, h_{0}\right.$ being the initial hydraulic head). However, investigations by Marino (1967) with similar analytical expressions showed that they give good results, even when the water table rise is much larger than the initial saturated thickness. This is consistent with the trials presented in Appendix C. Finally, the proposed solutions assume that the percolating water directly enters the aquifer. Extensions to account for noninstantaneous drainage from the vadose zone above the water table could be considered using Moench's (1996) solution.

In conclusion, the generic solution proposed above develops valid solutions for any surface geometry, not necessarily rectangular or circular, and for aquifer boundaries that are not necessarily parallel or at right angle to the basin geometry. In addition, the solution helps testing a large panel of hydrogeological settings, including a stream flowing on the top layer of a multi-layer aquifer that is recharged and pumped (with the solutions of Hunt, 2009), or where only the deep layer is pumped (Ward and Lough, 2011), or an aquifer that is recharged and where pumping takes place through a fracture (Dewandel et al., 2018). Future works should also focus on unconfined and anisotropic aquifers, with the problem that in this case hydraulic head depends on depth (Neuman, 1975).

\section{Acknowledgements}

This study was conducted by BRGM, and was funded by the internal BRGM RDI Recharging project and the 'Dem'Eaux Roussillon' project funded by BRGM, European Funds for Regional Development, Rhone Mediterranean \& Corsica Water Agency, Communauté urbaine Perpignan Méditerranée Métropole and the Pyrenées Orientales Department. The two anonymous Journal referees are thanked for their useful remarks and comments that improved the quality of the paper. We are grateful to Dr. H.M. Kluijver for revising the final version of the English text. A patent application has been deposited on parts of this work (French National Institute of Industrial Property). 


\section{References}

Aish, A.M., 2010. Simulation of groundwater mound resulting from proposed artificial recharge of treated sewage effluent case study - Gaza waste water treatment plan, Palestine. Geologia Croatica, 62-73. doi: 104154/gc.2010.04

Baumann, P., 1952, Groundwater movement controlled through spreading: Transactions, American Society of Civil Engineers, v. 117, p. 1024-1060.

Bhuiyan, C., 2015. An approach towards site selection for water banking in unconfined aquifers through artificial recharge. Journal of Hydrology, 523, 465-474. http://dx.doi.org/10.1016/j.jhydrol.2015.01.052.

Boisson, A., Baïsset, M., Alazard, M., Perrin, J., Villesseche, D., Dewandel, B., Kloppmann, W., Chandra, S., Picot-Colbeaux, G., Sarah, S., Ahmed, S., Maréchal, J.-C., 2014. Comparison of surface and groundwater balance approaches in the evaluation of managed aquifer recharge structures: Case of a percolation tank in a crystalline aquifer in India. Journal of Hydrology, 519, 1620-1633. http://dx.doi.org/10.1016/j.jhydrol.2014.09.022.

Bouwer, H., 2002. Artificial recharge of groundwater: hydrogeology and engineering. Hydrogeology Journal, 10, 121-142. DOI 10.1007/s10040-001-0182-4.

Bruggeman, G.A., 1999. Analytical Solutions of Geohydrological Problems. Developments in Water Science 46, Elsevier, The Netherlands, 959 p.

Carleton, G.B., 2010. Simulation of groundwater mounding beneath hypothetical stormwater infiltration basins: U.S. Geological Survey Scientific Investigations Report 2010-5102, 64 p.

Dewandel, B., Lanini, S., Lachassagne, P., Maréchal, J.C., 2018. A generic analytical solution for modelling pumping tests in wells intersecting fractures. Journal of Hydrology, 559, 89-99, https://doi.org/10.1016/j.jhydrol.2018.02.013

Dewandel, B., Aunay, B., Maréchal, J.C., Roques, C., Bour, O., Mougin, B., Aquilina, L., 2014. Analytical solutions for analysing pumping tests in a sub-vertical and anisotropic fault zone draining shallow aquifers. Journal of Hydrology , 509, 115-131.

Dillon, P., 2005. Future management of aquifer recharge, Hydrogeological Journal, 13, 313316, https://doi.org/10.1007/s10040-004-0413-6, 2005.

Dillon, P.J., Gale, I., Contreras, S., Pavelic, P., Evans, R., Ward, J., 2009. Managing aquifer recharge and discharge to sustain irrigation livelihoods under water scarcity and climate change. Retrieved from. IAHS-AISH Publication 330 (September), 1-12.

Ferris, J.G., Knowles, D.B., Brown, R.H., Stallman, R.W., 1962. Theory of aquifer tests. U.S. Geological Survey Water-Supply Paper, 69-174.

Finnemore, E.J., 1995. A program to calculate ground-water mound heights: Ground Water, 33, 139-143.

Ganot, Y., Holtzman, R., Weisbrod, N., Nitzan, I., Katz, Y., Kurtzman, D., 2017. Monitoring and modeling infiltration-recharge dynamics of managed aquifer recharge with desalinated seawater. Hydrol. Earth Syst. Sci., 21, 4479-4493. https://doi.org/10.5194/hess-21-4479-2017 
565 Glover, R.E., 1960, Mathematical derivations as pertain to groundwater recharge: Fort 566 Collins, Colorado, U.S. Department of Agriculture Agricultural Research Service, 81 p.

567 Glover, R.E., Balmer, C.G., 1954. River depletion from pumping a well near a river. 568 Transactions of the American Geophysical Union, 35(3), 468-470.

569 Hantush, M.S., 1964a. Hydraulics of Wells. In Advances in Hydroscience. v.1, ed. V.T. 570 Chow. Academic Press.

571 Hantush, M.S., 1964b. Depletion of storage, leakage, and river flow by gravity wells in 572 sloping sands. Journ. of Geophys. Research, 69 (12), 2551-2560.

573 Hantush, M.S., 1965. Wells near streams with semipervious beds. Journal of Geophysical 574 Research, 70 (12), 2829-2838.

575 Hantush, M.S., 1967, Growth and decay of groundwater mounds in response to uniform 576 percolation: Water Resources Research, 3, 227-234.

577 Hunt, B.W., 1971, Vertical recharge of unconfined aquifers: Journal of Hydraulic Division, 578 American Society of Civil Engineers, 97, no. HY7, 1017-1030.

579 Hunt, B., 1999. Unsteady stream depletion from ground water pumping. Ground Water, 37(1), $580 \quad 98-102$.

581 Hunt, B., 2009. Stream depletion in a two-layer leaky aquifer system. Journal of Hydrological 582 Engineering, 10.1061/(ASCE)HE.1943-5584.0000063, 895-903.

583 Hunt, B., 2014. Review of stream depletion solutions, behavior, and calculations. Journal of 584 Hydrological Engineering, 10.1061/(ASCE)HE.1943-5584.0000768, 167-178.

585

586

587

588

589

590

591

592

593

594

595

596

597

598

599

600

601
Hunt, B., Scott D., 2007. Flow to a well in a two-aquifer system. Journal of Hydrological Engineering, 10.1061/(ASCE)1084-0699(2007)12:2(146), 146-155.

Kacimov, A., Zlotnik, R.V., Al-Maktoumi, A., Al-Abri, R., 2016. Modeling of transient water table response to managed aquifer recharge: A lagoon in Muscat, Oman. Environmental Earth Sciences 75, 4: 318. DOI:https://doi.org/10.1007/s12665-015-5137-5.

Kruseman, G.P., de Ridder, N.A., 1994. Analysis and evaluation of pumping test data. ILRI publication 47. Wageningen, The Netherlands.

Latinopoulos, P., 1981. The response of groundwater on artificial recharges schemes. Water Resources Research, 17(6), 1712-1714.

Latinopoulos, P., 1984. Periodic recharge to finite aquifers from rectangular areas. Adv. Water Resources, 7, 137-140.

Lee, H., Koo, M.H., Oh, S., 2015. Modeling stream-aquifer interactions under seasonal groundwater pumping and managed aquifer recharge. Groundwater, 57 (2), 216-225. doi: 10.1111/gwat.12799

Lelièvre, R.F., 1969. Study of the influence of pumping in alluvial aquifers on the base flow of rivers - in French (Etude de l'influence de pompages en nappes alluviales sur le régime d'étiage du réseau superficiel). Report BRGM 69 SGL 073 HYD., 95 p. 
602

603

604

605

606

607

608

609

610

611

612

613

614

615

616

617

618

619

620

621

622

623

624

625

626

627

628

629

630

631

632

633

634

635

636

637

638

Manglik, A., Rai, S.N., Singh, R.N., 1997. Response of an unconfined aquifer induced by time varying recharge from a rectangular basin. Water Resources Management, 11, 185-196.

Manglik, A., Rai, S.N., Singh, R.N., 2004. Modelling of aquifer response to time varying recharge and pumping from multiple basins and wells. Journal of Hydrology 292, 23-29.

Marino, M.A., 1967. Hele-Shaw model study of the growth and decay of groundwater ridges. Journal of Geophysical Research, 72, 4, 1195-1205.

Marino, M.A., 1974. Growth and decay of groundwater mounds induced by percolation. Journal of Hydrology 22, 295-301.

Marino, M.A., 1975. Artificial groundwater recharge, i. Circular recharging area. Journal of Hydrology 25, 201-208.

Massuel, S., Perrin, J., Mascre, C., Mohamed, W., Boisson, A., Ahmed, S., 2014. Managed aquifer recharge in South India: What to expect from small percolation tanks in hard rock? Journal of Hydrology, 512, 157-167. https://doi.org/10.1016/j.jhydrol.2014.02.062.

Moench, A.F., 1996. Flow to well in a water-table aquifer: an improved Laplace transform solution. Ground Water, 34 (4), 593-596.

Molden, D., Sunada, D.K., Warner, J.W., 1984. Microcomputer model of artificial recharge using Glover's solution. Ground Water, Jan.-Feb. 1984, 73-79.

Neuman, S.P., 1972. Theory of flow in unconfined aquifers considering delayed response of the water table. Water Resources Research, 8, no. 4: 1031-1045.

Nicolas, M., Bour, O., Selles, A., Dewandel, B., Bailly-Comte, V., Chandra, S., Ahmed, S., Maréchal, J.-C., 2019. Managed aquifer recharge in fractured crystalline rock aquifers: Impact of horizontal preferential flow on recharge dynamics. Journal of Hydrology 573, 717-732. https://doi.org/10.1016/j.jhydrol.2019.04.003.

Polubarinova-Kochina, P.Y. 1977. Theory of Ground Water Movement. Moscow: Nauka, in Russian. 665 p.

Rao, N.H., Sarma, P.B.S., 1981. Ground-water recharge from rectangular areas: Ground Water, 19, no. 3, 270-274.

Rao, N.H., Sarma, P.B.S., 1984. Recharge to aquifers with mixed boundaries. Journal of Hydrology, 74, 43-51.

Rai, S.N., Singh, R. N., 1996. On the prediction of groundwater mound formation due to transient recharge from a rectangular area. Water Resources Management, 10: 189-198.

Rai, S.N., Ramana, D.V., Singh, R.N., 1998. On the prediction of ground-water mound formation in response to transient recharge from a circular basin. Water Resources Management 12, 271-284.

Rai, S.N., Ramana, D.V., Thiagarajan, S., Manglik, A., 2001. Modelling of groundwater mound formation resulting from transient recharge. Hydrol. Process. 15, 1507-1514. DOI: 10.1002/hyp. 222 
639 Stafford, N., Che, D., Mays, L.W., 2015. Optimization model for the design of infiltration 640 basins. Water Resouces. Management, 29, 2789-2804. DOI 10.1007/s11269-015-0970-6

641 Theis, C.V., 1935. The relation between the lowering of the piezometric surface and the rate 642 and duration of discharge of a well using groundwater storage. Transactions of the American 643 Geophysical Union, 16, 519-524.

644 Theis, C.V., 1941. The effect of a well on the flow of a nearby stream. Transactions of the 645 American Geophysical Union, 22, 734-738.

646 Ward, N.D., Lough, H., 2011. Stream depletion from pumping a semiconfined aquifer in a 647 two-layer leaky aquifer system. Journal of Hydrologic Engineering, 16 (11), 955-959.

648 Warner, J.W., Molden, D., Mondher, C., D.K. Sunada, 1989, Mathematical analysis of 649 artificial recharge from basins: Water Resources Bulletin, 25 (2), 401-411.

650 Yihdego, Y., 2017. Simulation of groundwater mounding due to irrigation practice: case of 651 wastewater reuse engineering design, Hydrology, 4, 19, 1-10. doi:10.3390/hydrology4020019

652 Zlotnik, V.A., Kacimov, A., Al-Maktoumi, A., 2017. Estimating groundwater mounding in 653 sloping aquifers for managed aquifer recharge. Ground Water, 55 (6), 797-810. doi: 654 10.1111/gwat.12530

655 Zomorodi, K., 2005. Simplified solutions for groundwater mounding under stormwater 656 infiltration facilities: Proceedings of the American Water Resources Association 2005 annual 657 Water Resources Conference, November 7-10, 2005, Seattle, Washington, 4 p. 


\section{APPENDICES}

\section{Appendix A.}

661 A-1. Groundwater flow of groundwater mounding for a rectangular basin with a uniform 662 percolation rate (Fig.2) is defined by the following nonlinear Boussinesq equation:

$663 \frac{\partial}{\partial x}\left(K h \frac{\partial h}{\partial x}\right)+\frac{\partial}{\partial y}\left(K h \frac{\partial h}{\partial y}\right)+R=S \frac{\partial h}{\partial t}$

664 With $K$ the hydraulic conductivity of the aquifer, $S$ the aquifer storativity and $R$ the recharging 665 rate.

666 Boundary conditions are $h(x, y, 0)=h_{0} ; h( \pm \infty, y, t)=h(x, \pm \infty, t)=h_{0}$

667 Defining $Z=h^{2}-h_{0}{ }^{2}$, and assuming a homogeneous and isotropic aquifer ( $K=$ constant), 668 Hantush (1967) obtained the following approximate partial differential equation:

670 with $h-h_{0}<0.5 h_{0}, v=\frac{K \bar{b}}{S}, \bar{b}$ is a constant of linearization $\bar{b}=\frac{1}{2}\left(h_{0}+h_{t}\right)$.

671 Boundary conditions: $Z(x, y, 0)=0 ; Z( \pm \infty, y, t)=Z(x, \pm \infty, t)=0 ; \frac{\partial Z(0, y, t)}{\partial x}=\frac{\partial Z(x, 0, t)}{\partial y}=0$

672

673

674

675

676

677

678

679

680

681

682

683

684

A-2. Hantush's approximate partial differential equation for a well pumping an unconfined, infinite and horizontal aquifer (Hantush, 1964, 1965).

$\frac{\partial^{2} Z}{\partial x^{2}}+\frac{\partial^{2} Z}{\partial y^{2}}=\frac{1}{v} \frac{\partial Z}{\partial t}$

$Z=h^{2}-h_{0}^{2}$, with $h_{0}-h<0.5 h_{0}$

Boundary conditions:

$Z(x, y, 0)=0 ; Z( \pm \infty, y, t)=Z(x, \pm \infty, t)=0 ; \operatorname{Lim}_{r \rightarrow 0} r \frac{\partial Z}{\partial r}=\frac{Q_{P u m p}}{\pi K}$

$Q_{\text {Pump }}$ is the pumping rate $(<0)$ and $r$ the distance to the pumping well.

\section{Appendix B.}

Integration of Eq. 1 into a rectangular surface of lengths $2 x_{L} \times 2 y_{L}$ and considering that the recharging rate, $R$, is uniformly distributed on the rectangular recharging area $\left(2 x_{L} \times 2 y_{L}\right)$, i.e. $R=\frac{Q_{\text {Rech }}}{4 x_{L} y_{L}}$, Eq.2 becomes:

$Z_{\text {Rech }}\left(x_{o b s}, y_{o b s}, t\right)=h^{2}-h_{o}{ }^{2}=\frac{R}{2 \pi K} \int_{-x_{L}}^{+x_{L}} \int_{-y_{L}}^{+y_{L}} W\left(\frac{\left(x-x_{o b s}\right)^{2}+\left(y-y_{o b s}\right)^{2}}{4 v t}\right) d x d y$ 
686 Then, because of the properties of exponential integrals $\left[W\left(\frac{a}{t}\right)=\int_{a / t}^{\infty} \frac{e^{-y}}{y} d y=\int_{0}^{t} \frac{e^{-a / \tau}}{\tau} d \tau\right]$, 687 it follows

$Z_{\text {Rech }}\left(x_{o b s}, y_{o b s}, t\right)=\frac{R}{2 \pi K} \int_{-x_{L}}^{+x_{L}} \int_{-y_{L}}^{+y_{L}} \int_{0}^{t} \frac{e^{\frac{-\left(x-x_{o b s}\right)^{2}-\left(y-y_{o b s}\right)^{2}}{4 v \tau}}}{\tau} d \tau d x d y$

According to the Fubini theorem (i.e. $t, x$ and $y$ are independent variables), the order of 690 integration can be inverted, resulting in:

$Z_{\text {Rech }}\left(x_{o b s}, y_{o b s}, t\right)=\frac{R}{2 \pi K} \int_{0}^{t} \underbrace{\int_{-x_{L}}^{+x_{L}} \frac{e^{\frac{-\left(x-x_{o b s}\right)^{2}}{4 v \tau}}}{\sqrt{\tau}}} d x \underbrace{\int_{-y_{L}}^{+y_{L}} \frac{e^{\frac{-\left(y-y_{o b s}\right)^{2}}{4 v \tau}}}{\sqrt{\tau}}} d y d \tau$

693 Performing a change of variable $\vartheta=\frac{\left(x-x_{o b s}\right)}{2 \sqrt{v t}}$, the (a) term in Eq. B-3 can be rewritten as:

$$
\int_{-x_{L}}^{+x_{L}} \frac{e^{\frac{-\left(x-x_{o b s}\right)^{2}}{4 v \tau}}}{\sqrt{\tau}} d x=\int_{-\left(x_{L}+x_{o b s}\right) / 2 \sqrt{v \tau}}^{\left(x_{L}-x_{o b s}\right) / 2 \sqrt{v \tau}} 2 \sqrt{v} e^{-\vartheta^{2}} d \vartheta
$$

The right part in Eq. B-4 can be separated into two terms related to the Erf function

$\left[\int_{a}^{b} e^{-u^{2}} d u=\frac{\sqrt{\pi}}{2}[\operatorname{Erf}(u)]_{a}^{b}=\frac{\sqrt{\pi}}{2}(\operatorname{Erf}(b)-\operatorname{Erf}(a))\right]$, therefore:

$$
\int_{-\left(x_{L}+x_{o b s}\right) / 2 \sqrt{v \tau}}^{\left(x_{L}-x_{o b s}\right) / 2 \sqrt{v \tau}} 2 \sqrt{v} e^{-\vartheta^{2}} d \vartheta=\sqrt{\pi v}\left[\operatorname{Erf}\left(\frac{x_{L}+x_{o b s}}{2 \sqrt{v \tau}}\right)+\operatorname{Erf}\left(\frac{x_{L}-x_{o b s}}{2 \sqrt{v \tau}}\right)\right]
$$

698 Changing the variable $\vartheta^{\prime}=\frac{\left(y-y_{o b s}\right)}{2 \sqrt{v t}}$ on term (b) in Eq. B-3, and using the same procedure as 699 described before, the (b) term can be rewritten

$$
\int_{-y_{L}}^{+y_{L}} \frac{e^{\frac{-\left(y-y_{o b s}\right)^{2}}{4 v t}}}{\sqrt{\tau}} d x=\sqrt{\pi v}\left[\operatorname{Erf}\left(\frac{y_{L}+y_{o b s}}{2 \sqrt{v \tau}}\right)+\operatorname{Erf}\left(\frac{y_{L}-y_{o b s}}{2 \sqrt{v \tau}}\right)\right]
$$


701 Finally, combining equations B-5 and B-6, and since $v=\frac{K \bar{b}}{S}$, we obtain:

$$
\begin{aligned}
Z_{\text {Rech }}\left(x_{o b s}, y_{o b s}, t\right) & =h^{2}-h_{o}{ }^{2} \\
= & \frac{R \bar{b}}{2 S} \int_{0}^{t}\left[\operatorname{Erf}\left(\frac{x_{L}+x_{o b s}}{2 \sqrt{v \tau}}\right)+\operatorname{Erf}\left(\frac{x_{L}-x_{o b s}}{2 \sqrt{v \tau}}\right)\right] \times\left[\operatorname{Erf}\left(\frac{y_{L}+y_{o b s}}{2 \sqrt{v \tau}}\right)+\operatorname{Erf}\left(\frac{y_{L}-y_{o b s}}{2 \sqrt{v \tau}}\right)\right] d \tau
\end{aligned}
$$

Equation B-7 demonstrates that the well solution for an unconfined and isotropic aquifer (Hantush, 1964a, 1965) integrated into a rectangular plane is exactly the same as Hantush's analytical solution for a rectangular recharging area with a uniform distribution of the recharge flux (Eq. 13 in Hantush, 1967).

\section{Appendix C.}

The hydraulic-head solution for a rectangular recharging area and a pumping well between two parallel boundaries (constant head or no-flow boundary).

$x_{w}$ and $y_{w}$ : coordinates of the pumping well, $d$ : the distance between the centre of the recharging area and the stream. $2 L$ is the distance between both limits. $x=y=0$ at the centre of the recharging area. $v=\frac{K \bar{b}}{S}$. Below are presented the general solutions for hydraulic head between two parallel limits; $b$ and $c$ are coefficients, $b$ or $c=1$ for a no-flow boundary, and $b$ or $c=-1$ for is a constant-head boundary (Dirichlet's condition).

. 
$\underline{\text { Term for the pumping well: }}$

$$
\begin{aligned}
& Z_{2 \text { Limit_Pump }}\left(x_{o b s}, y_{o b s}, t\right)=h^{2}-h_{o}{ }^{2} \\
&= \frac{Q}{2 \pi K}\left\{W\left(\frac{\left(x_{o b s}-x_{w}\right)^{2}+\left(y_{o b s}-y_{w}\right)^{2}}{4 v t}\right)\right. \\
&+\sum_{n=0,2,4 . .}^{\infty} b^{n / 2+1} c^{n / 2} W\left(\frac{\left(2 n L+2 d-x_{o b s}+x_{w}\right)^{2}+\left(y_{o b s}-y_{w}\right)^{2}}{4 v t}\right) \\
&+\sum_{n=2,4 . .}^{\infty}(b c)^{n / 2} W\left(\frac{\left(-2 n L-x_{o b s}+x_{w}\right)^{2}+\left(y_{o b s}-y_{w}\right)^{2}}{4 v t}\right) \\
&+\sum_{n=2,4 . .}^{\infty}(b c)^{n / 2} W\left(\frac{\left(2 n L-x_{o b s}+x_{w}\right)^{2}+\left(y_{o b s}-y_{w}\right)^{2}}{4 v t}\right) \\
&\left.+\sum_{n=2,4 . .}^{\infty} b^{n / 2-1} c^{n / 2} W\left(\frac{\left(-2 n L+2 d-x_{o b s}+x_{w}\right)^{2}+\left(y_{o b s}-y_{w}\right)^{2}}{4 v t}\right)\right\}
\end{aligned}
$$

Term for the rectangular recharging area:

$$
\begin{aligned}
&\left.Z_{2 L i m i t_{\text {Rech }}\left(x_{o b s}, y_{o b s},\right.} t\right)=h^{2}-h_{o}{ }^{2} \\
&= \frac{R \bar{b}}{2 S}\left\{\int_{0}^{t}\left[\operatorname{Erf}\left(\frac{x_{L}+x_{o b s}}{2 \sqrt{v \tau}}\right)+\operatorname{Erf}\left(\frac{x_{L}-x_{o b s}}{2 \sqrt{v \tau}}\right)\right] \times\left[\operatorname{Erf}\left(\frac{y_{L}+y_{o b s}}{2 \sqrt{v \tau}}\right)+\operatorname{Erf}\left(\frac{y_{L}-y_{o b s}}{2 \sqrt{v \tau}}\right)\right] d \tau\right. \\
&+\sum_{n=0,2,4 . .}^{\infty} b^{n / 2+1} c^{n / 2} \int_{0}^{t}\left[\operatorname{Erf}\left(\frac{x_{L}+2 n L+2 d-x_{o b s}}{2 \sqrt{v \tau}}\right)+\operatorname{Erf}\left(\frac{x_{L}-2 n L-2 d+x_{o b s}}{2 \sqrt{v \tau}}\right)\right] \\
& \times\left[\operatorname{Erf}\left(\frac{y_{L}+y_{o b s}}{2 \sqrt{v \tau}}\right)+\operatorname{Erf}\left(\frac{y_{L}-y_{o b s}}{2 \sqrt{v \tau}}\right)\right] d \tau \\
&+\sum_{n=2,4 . .}^{\infty}(b c)^{n / 2} \int_{0}^{t}\left[\operatorname{Erf}\left(\frac{x_{L}-2 n L-x_{o b s}}{2 \sqrt{v \tau}}\right)+\operatorname{Erf}\left(\frac{x_{L}+2 n L+x_{o b s}}{2 \sqrt{v \tau}}\right)\right] \\
& \times\left[\operatorname{Erf}\left(\frac{y_{L}+y_{o b s}}{2 \sqrt{v \tau}}\right)+\operatorname{Erf}\left(\frac{y_{L}-y_{o b s}}{2 \sqrt{v \tau}}\right)\right] d \tau \\
&+\sum_{n=2,4 . .}^{\infty}(b c)^{n / 2} \int_{0}^{t}\left[\operatorname{Erf}\left(\frac{x_{L}+2 n L-x_{o b s}}{2 \sqrt{v \tau}}\right)+\operatorname{Erf}\left(\frac{x_{L}-2 n L+x_{o b s}}{2 \sqrt{v \tau}}\right)\right] \\
& \times\left[\operatorname{Erf}\left(\frac{y_{L}+y_{o b s}}{2 \sqrt{v \tau}}\right)+\operatorname{Erf}\left(\frac{y_{L}-y_{o b s}}{2 \sqrt{v \tau}}\right)\right] d \tau \\
&+\sum_{n=2,4 . .}^{\infty} b^{n / 2-1} c^{n / 2} \int_{0}^{t}\left[\operatorname{Erf}\left(\frac{x_{L}-2 n L+2 d-x_{o b s}}{2 \sqrt{v \tau}}\right)+\operatorname{Erf}\left(\frac{x_{L}+2 n L-2 d+x_{o b s}}{2 \sqrt{v \tau}}\right)\right] \\
&\left.\times\left[\operatorname{Erf}\left(\frac{y_{L}+y_{o b s}}{2 \sqrt{v \tau}}\right)+\operatorname{Erf}\left(\frac{y_{L}-y_{o b s}}{2 \sqrt{v \tau}}\right)\right] d \tau\right\}
\end{aligned}
$$

730 The graph below compares the solution Eq. C-2 with $b=-1, c=1,2 x_{L}=2 L, d=L, \mathrm{y}_{\mathrm{L}} \rightarrow \infty$ and $t \rightarrow \infty$, to Bruggeman's steady-state solution (1999; sol. 21.11, p.24). This case corresponds to the hydraulic-head profile caused by recharge from precipitation $(R)$ through an infinite strip of width $2 L$ bounded on one side by a stream and on the other by a no-flow boundary. Aquifer parameters are: $K=10^{-4} \mathrm{~m} / \mathrm{s}, S=0.05,2 L=800 \mathrm{~m}, R=1.27 \times 10^{-8} \mathrm{~m} / \mathrm{s}$ (or $400 \mathrm{~mm} /$ year), and $h_{0}$ 
varying from 1.5 to $12 \mathrm{~m}$. The insert shows standardized Root Mean Square Error values (RMSE-D) for the five cases.

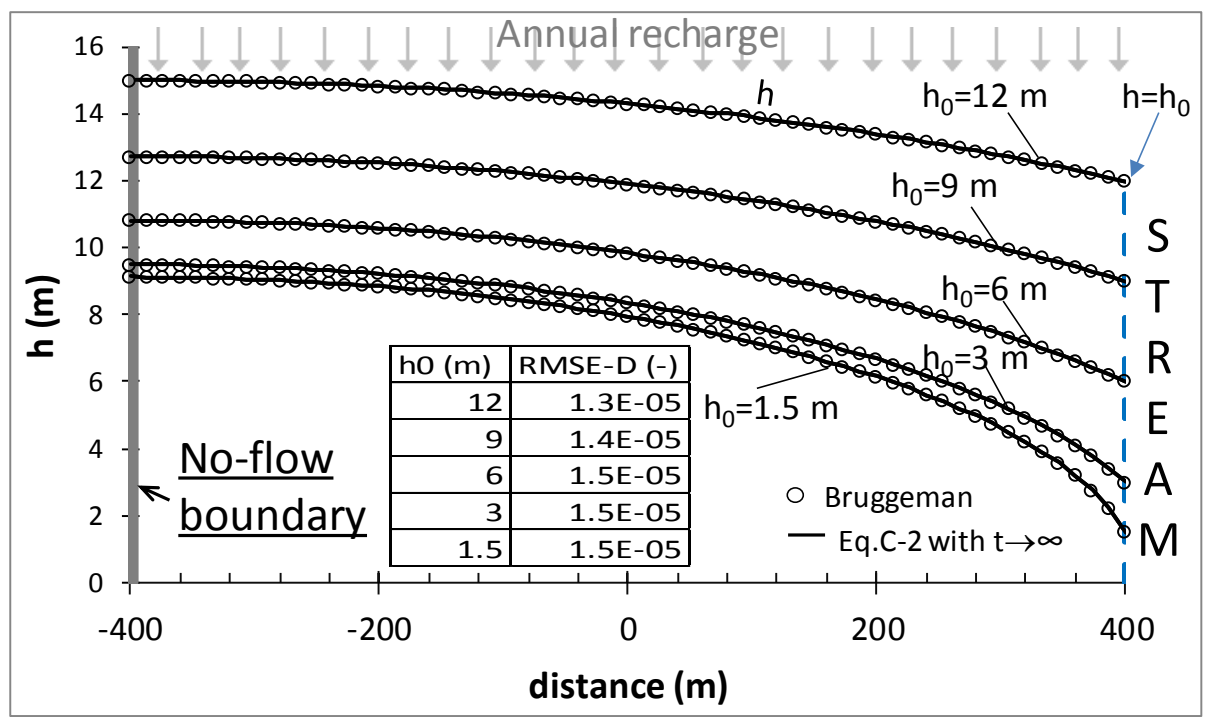

\section{Appendix D.}

The hydraulic-head solution for a pumping well near a stream with a partially clogged streambed that partially penetrates the aquifer (Hunt, 1999), modified for an unconfined condition (linearized Boussinesq solution as in Hantush 1967) is:

$$
\begin{aligned}
Z_{\text {HuntPump }}\left(x_{o b s}, y_{o b s}, t\right) & =h^{2}-h_{o}{ }^{2} \\
= & \frac{Q_{\text {Pump }}}{2 \pi K}\left[W\left(\frac{x_{o b s}{ }^{2}+y_{o b s}{ }^{2}}{4 v t}\right)-\int_{0}^{\infty} e^{-\theta} W\left(\frac{\left(d+\left|d-x_{o b s}\right|+2 K \bar{b} \theta / \lambda\right)^{2}+y_{o b s}{ }^{2}}{4 v t}\right) d \theta\right]
\end{aligned}
$$

with $\lambda=\frac{b}{b^{\prime \prime}} k^{\prime \prime} ; b$ : stream width, $b^{\prime \prime}:$ streambed thickness and $k^{\prime \prime}:$ streambed hydraulic conductivity.

The right part of Eq. D-1 can be rearranged with the following change of variable $\theta=-\operatorname{Ln}(u) \quad$ then $=-\frac{1}{u} d u ; \operatorname{Ln}=$ natural logarithm.

Then Eq. D-1 becomes:

$$
\begin{aligned}
& Z_{\text {HuntPump }}\left(x_{o b s}, y_{o b s}, t\right)=h^{2}-h_{o}{ }^{2} \\
& =\frac{Q}{2 \pi K}\left[W\left(\frac{x_{o b s}{ }^{2}+y_{o b s}{ }^{2}}{4 v t}\right)-\int_{0}^{1} W\left(\frac{\left(d+\left|d-x_{o b s}\right|-2 K \bar{b} \operatorname{Ln}(u) / \lambda\right)^{2}+y_{o b s}{ }^{2}}{4 v t}\right) d u\right]
\end{aligned}
$$


750

751

752

753

754

755

756

757

758

759

760

761

762

763

764

765

766

767

768

769

770

771

772

773

774

775

776

777

778

779

780

781

\section{Figure captions}

Figure 1. Conceptual models of the theoretical examples presented. a) Recharging and pumping an isotropic aquifer near a stream (Dirichlet's condition). b) Recharging and pumping an isotropic aquifer limited in space by a stream (Dirichlet's condition) and a noflow boundary (strip aquifer), with and without the influence of natural recharge. c) Recharging and pumping an aquifer near a stream with a clogged streambed that partially penetrates the aquifer. d) Recharging an unconfined and isotropic top layer aquifer and pumping a bottom semi-confined aquifer.

Figure 2. Definition sketch (plan and section views) of the Hantush's (1967) conceptual model of groundwater mounding from a rectangular recharging area.

Figure 3. Definition sketch of: a) recharging and pumping an isotropic aquifer near a stream, b) recharging and pumping an isotropic aquifer limited in space by a stream (Dirichlet's condition) and a no-flow boundary (strip aquifer). Similar to Figs. 1a and b.

Figure 4. Hydraulic-head profiles after 60 days (a and c), and impacts on streamflow rate (b and $\mathrm{d}$; <0: decrease of streamflow rate and >0: increase). a) and b) Recharging and pumping an isotropic aquifer near a stream (refer to Figs. 1a and 3a). c) and d) Recharging and pumping an isotropic aquifer limited in space by a river and a no-flow boundary (strip aquifer, refer to Figs. $1 \mathrm{~b}$ and $3 \mathrm{~b}) . K=10^{-4} \mathrm{~m} / \mathrm{s}, S=0.05, h_{0}=12 \mathrm{~m}, x_{L}=y_{L}=40 \mathrm{~m}, R=2.96 \times 10^{-6} \mathrm{~m} / \mathrm{s}$ and $Q_{\text {Pump }}=17 \mathrm{~m}^{3} / \mathrm{h}$.

Figure 5. Recharging and pumping an isotropic aquifer limited in space by a stream and a noflow boundary (strip aquifer) with the influence of natural recharge, hydraulic head profiles.

a) Without pumping, in this case the solution is identical Bruggeman (1999) solution (standardized RMSE $=2.22 \times 10^{-5} \mathrm{~m}$ ). b) With a recharging area and a pumping well at $140 \mathrm{~m}$ from the centre of the recharging area after 1 day and 60 days of recharging and pumping. $K=10^{-4} \mathrm{~m} / \mathrm{s}, S=0.05, h_{0}=12 \mathrm{~m}, x_{L}=y_{L}=40 \mathrm{~m}, R=2.96 \times 10^{-6} \mathrm{~m} / \mathrm{s}, Q_{\text {Pump }}=17 \mathrm{~m}^{3} / \mathrm{h}$ and $R_{\text {NatRech }}=1.27 \times 10^{-8} \mathrm{~m} / \mathrm{s}$.

Figure 6. Recharging and pumping an isotropic aquifer near a stream that partially penetrates the aquifer with clogged streambed (Fig. 1c). a) Hydraulic head profile after 60 days. b) 
782 Impact on streamflow rate, for various stream-leakance coefficients $\left(\lambda=\infty, 10^{-4}, 5.10^{-5}, 10^{-5}\right.$, $7835.10^{-6}$ and $\left.10^{-6} \mathrm{~m} / \mathrm{s}\right)$. Stream width: $10 \mathrm{~m}, K=10^{-4} \mathrm{~m} / \mathrm{s}, S=0.05, h_{0}=12 \mathrm{~m}, x_{L}=y_{L}=40 \mathrm{~m}$, $784 R=2.96 \times 10^{-6} \mathrm{~m} / \mathrm{s}$ and $Q_{\text {Pump }}=17 \mathrm{~m}^{3} / \mathrm{h}$.

785

786 Figure 7. Multi-aquifer system, recharging the top aquifer and pumping the deepest one. a) 787 Hydraulic-head profiles in the upper aquifer and b) drawdown of water level in the deeper 788 aquifer after 1 day and 60 days. c) Total drainage flow-rate induced by the recharging area 789 and by the pumping well, compared to the case with the recharging area only (without 790 pumping well). $K_{l}=10^{-4} \mathrm{~m} / \mathrm{s}, S_{1}=0.05, h_{0}=12 \mathrm{~m}, T_{2}=10^{-4} \mathrm{~m}^{2} / \mathrm{s}, S_{2}=10^{-3}, \mathrm{k}^{\prime} / \mathrm{e}^{\prime}=5 \times 10^{-7} \mathrm{~m}^{2} / \mathrm{s}$, $791 x_{L}=y_{L}=40 \mathrm{~m}, R=2.96 \times 10^{-6} \mathrm{~m} / \mathrm{s}$ and $Q_{\text {Pump }}=17 \mathrm{~m}^{3} / \mathrm{h}$. 

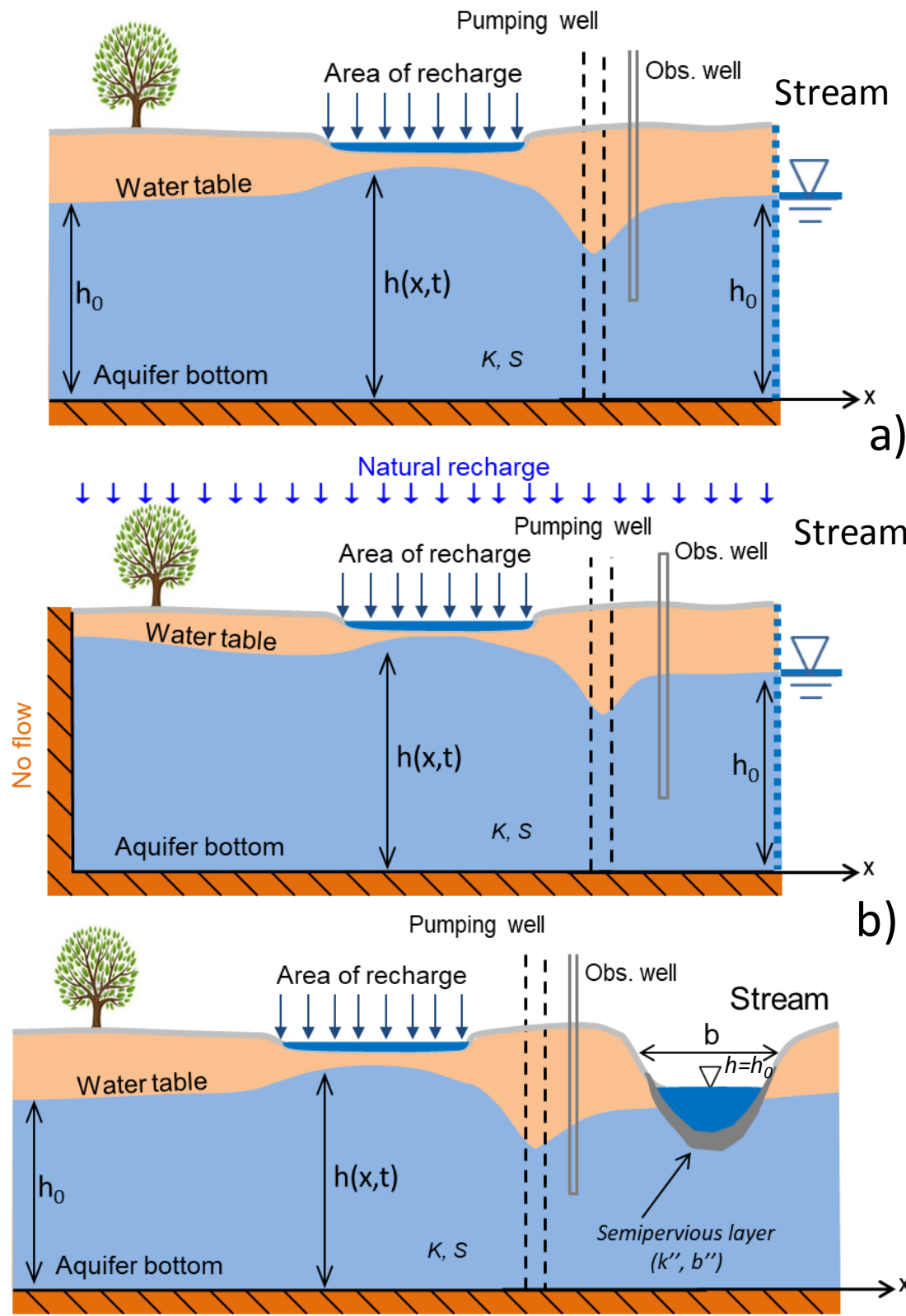

Fig.1

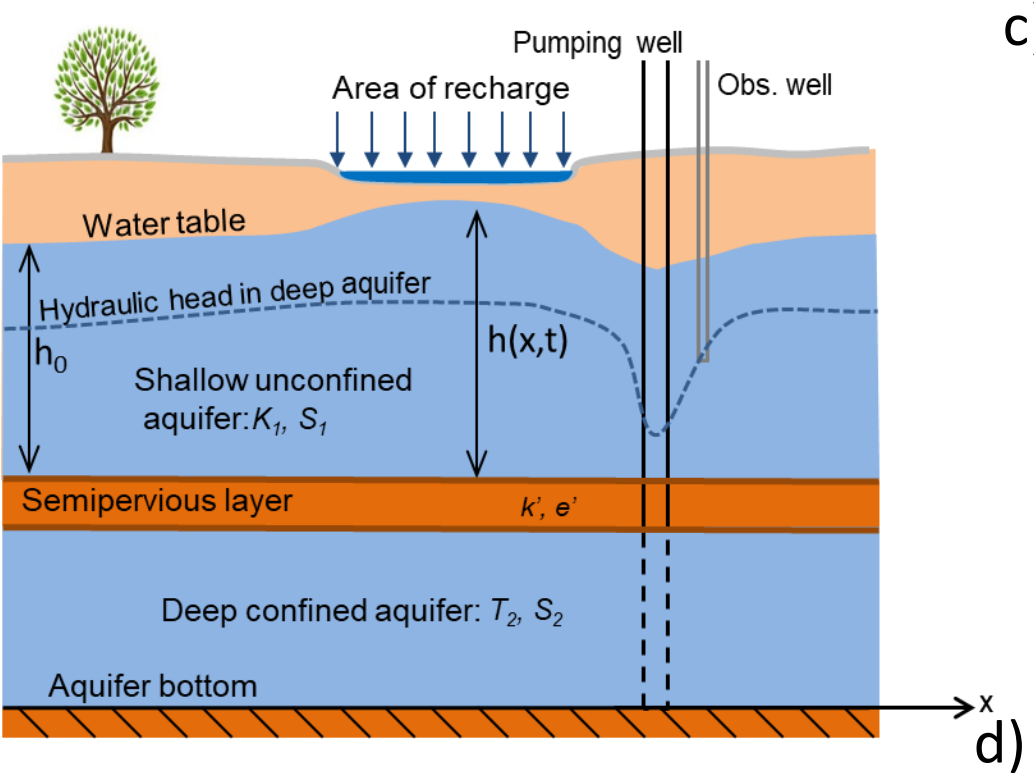



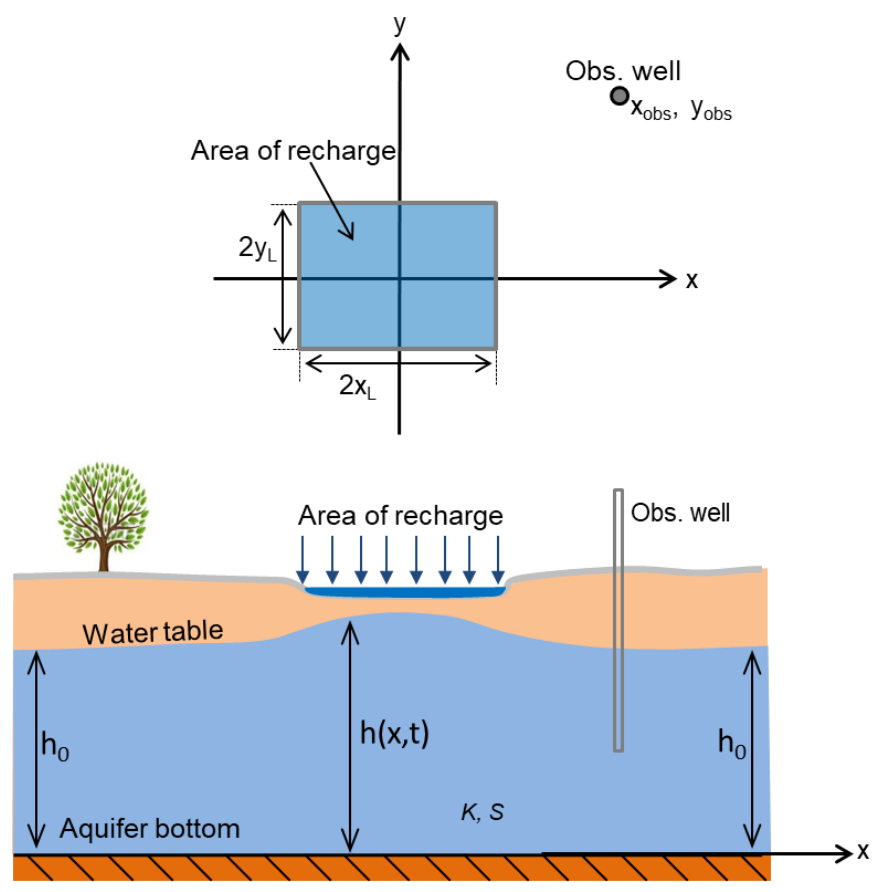

\section{Fig.2}

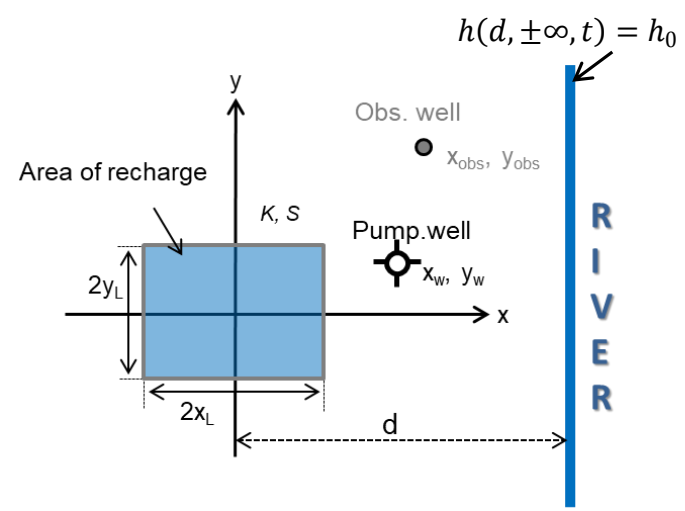

a)

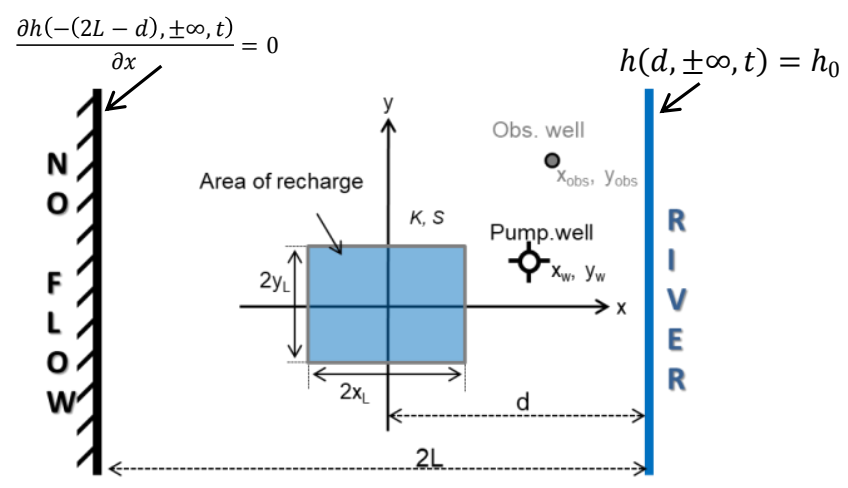

b)

Fig.3 

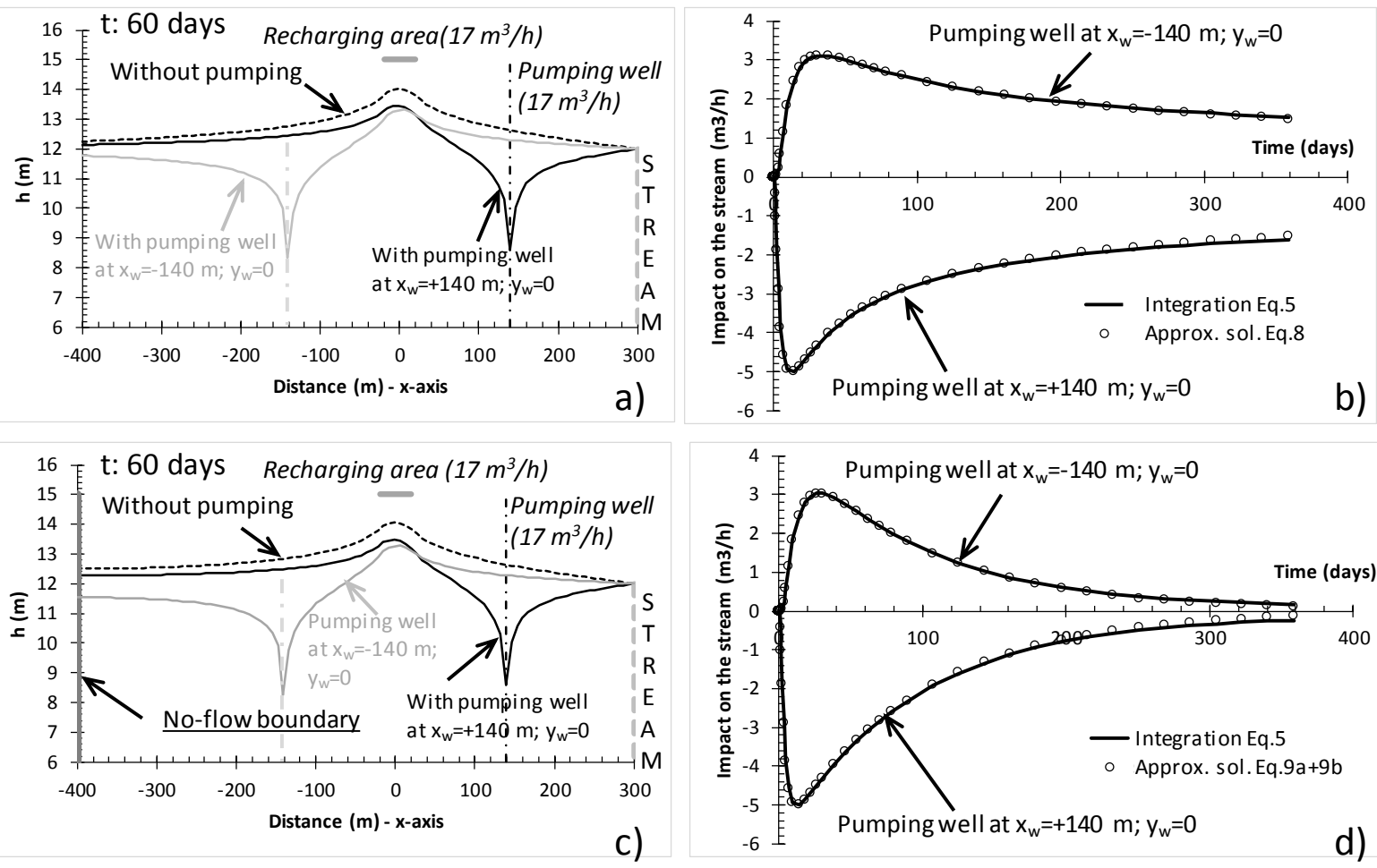

Fig.4 


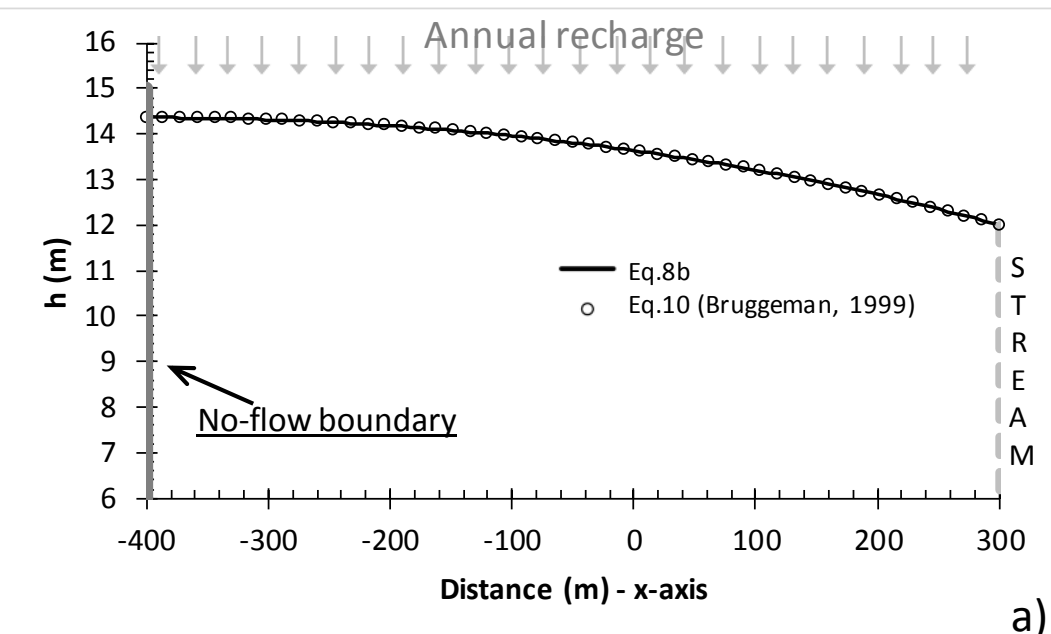

a)

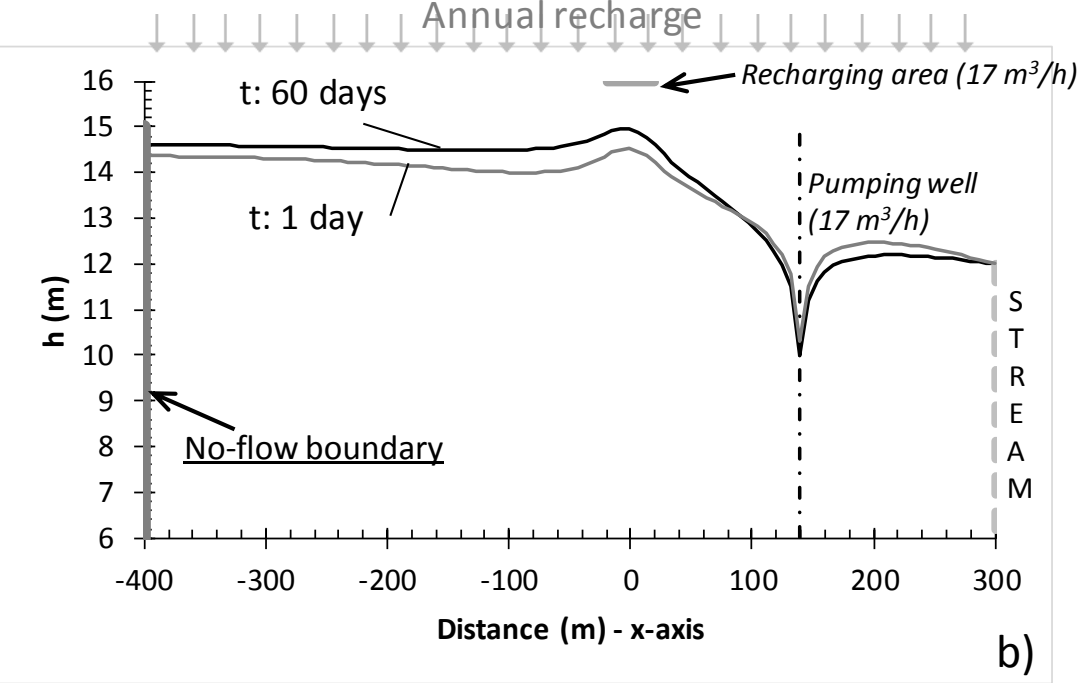

Fig.5

800

801

802

803 

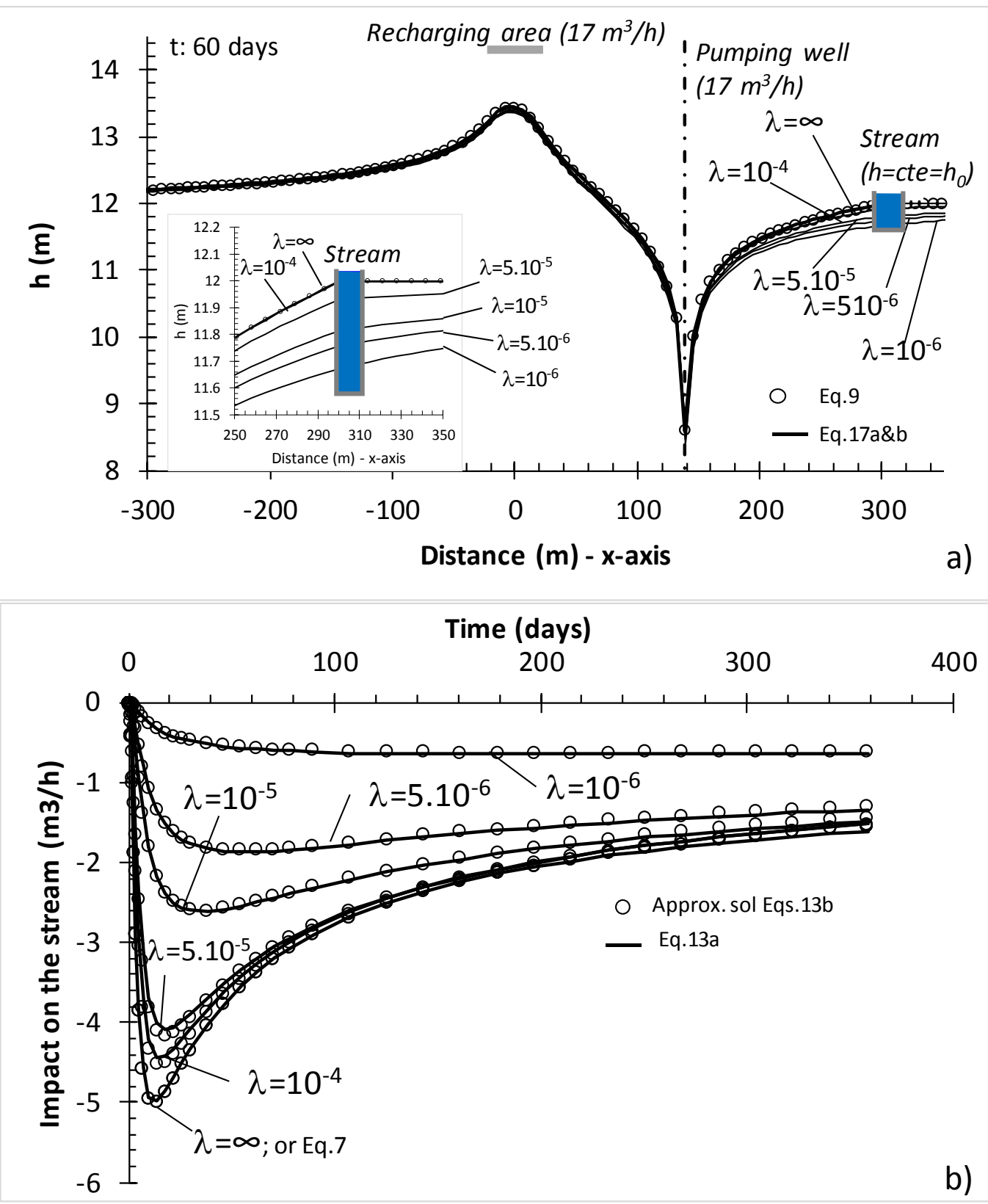

Fig.6

804 

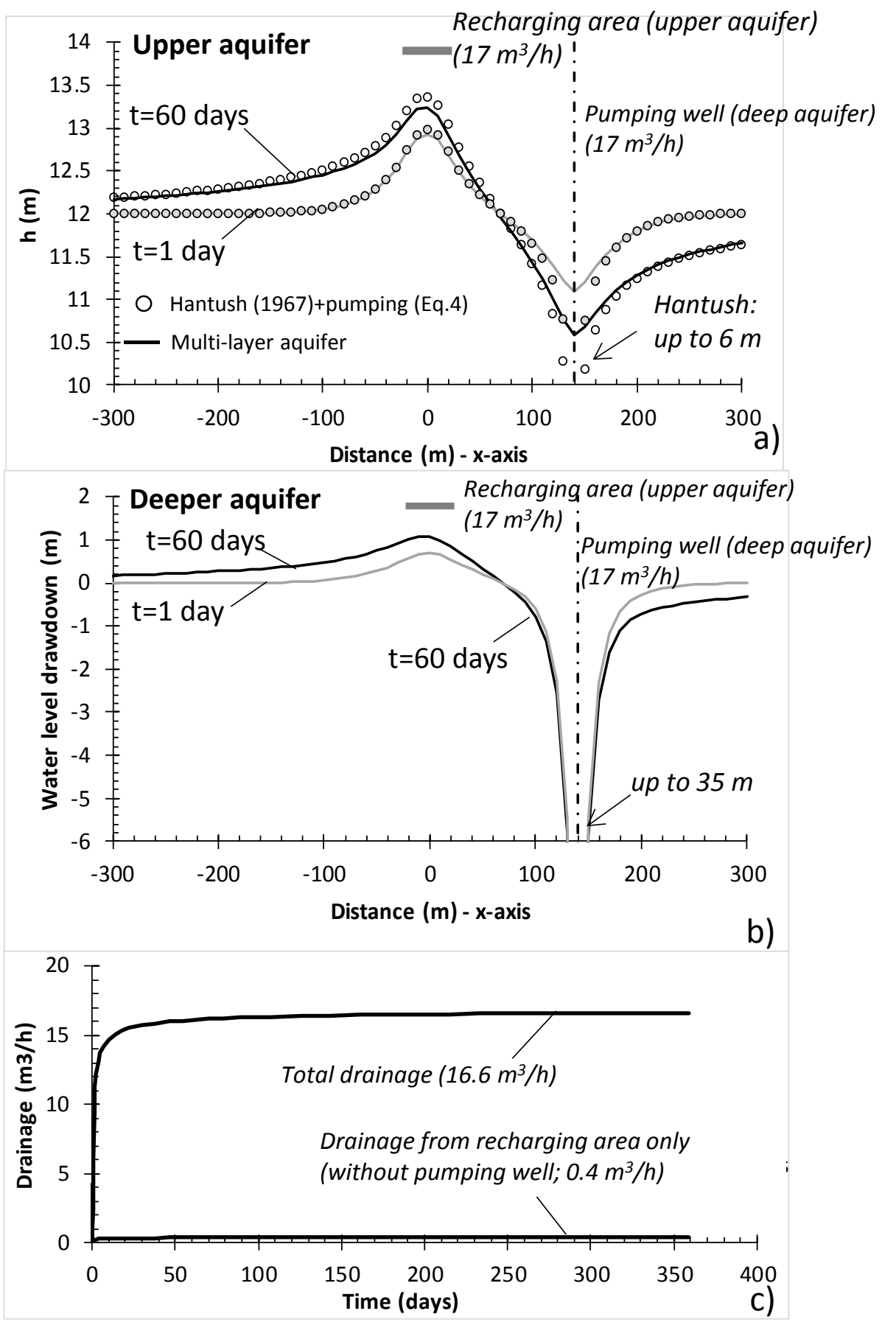

Fig.7

806 